
refinement of large-scale income-expenditure macroeconometric models, the attempt to reconcile the policy multipliers derived from these models with those yielded by simple reduced-forms, the refinement and estimation of the relation between inflation and unemployment, and the application of optimal control techniques to macroeconometric models. These four themes provide the focus for this paper.

The first section reviews the implications of various macroeconometric models for monetary and fiscal multipliers. We are particuTarly concerned here with the degree of consensus across models and the evolution of estimated models over time. The second section discusses attempts to reconcile the divergent implications of income-expenditure structural models and the $S t$. Louis reduced-form for fiscal policy multipliers. In the third section we develop the implications of estimated Phillips curve equations and monetarist models for the response of unemployment, output, and inflation to traditional demand management policies. And in the fourth section we consider the accuralated evidence on the gains from policy activism, drawing on the results of optimal control simulations with a variety of macroeconometric models.

Laurence $H$. Meyer is Associate Professor of Economics at Washington University and Visiting Scholar at the Federal Reserve Bank of St. Louis. Robert H. Rasche is Professor of Economics at Michigan State University. 
During the last half of the 170 s increased attention has been focused on the way in which economic agents form expectations, particum larly inflation expectations, and on "equilibrium" macroecononic nodels embodying "rational expectations." These models yield dramatic conclusions about both the costs of eradicating inflation and the gains from activism. We therefore consider the implications of rational expectation models in both the third and fourth sections, although there is as yet only a smal1 literature on empjrical applications of these models to draw upon.

A COMPARISON OF POLICY MULTIPLIERS ACROSS MODELS AND TIME

In this section we review the evidence from structurat modeis and reduced-forms about the size and time pattern of policy multipliers. We are interested in the average size of multipliers, the consensus across models, and the evolution over time in the estimated multipliers.

\section{A Comparison of Multipliers Across Models}

Christ (1975) has summarized the consensus across models rather pessimistical1y: "... though models forecast reasonably well over horizons of four to six quarters, they disagree so strongly about the effects of important monetary and fiscal policies that they cannot be considered reliable guides to such policy effects, until it can be determined which of them are wrong in this respect and which (if any) are right." (p. 54)

Tables 1, 2, and 3 present policy multipliers from seven econometric models (Bureau of Economic Analysis (BEA), Brookings (B), University of Michigan (MQEM), Data Resources, Inc. (DRI), Federal Reserve Bank of St. Louis (St.L), MIT-Pennsylvania-SSRC (MPS), and Wharton (W)) 
as reported in Fromm and klein (1976). The multipliers are reported for the first quarter and fourth, eighth, twelfth, sixteenth, and twentieth quarters and for three policy changes - an increase in real government expenditures on goods and services, a dectine in personal taxes, and an increase in either the money supply or nonborrowed rem serves. The mean and coefficients of variation for the various multipliers are also reported. '

TABLE 1

Fiscal Policy - Increase in Government Expenditures

Model IC* $\operatorname{RMSE}(4 Q) *$ Multiplier

\begin{tabular}{|c|c|c|c|c|c|c|c|c|}
\hline & & & 10 & $4 Q$ & $8 Q$ & 120 & $16 \mathrm{Q}$ & 200 \\
\hline$B E A$ & 62 & 6.94 & 1.1 & 2.2 & 2.2 & 1.8 & 1.6 & 1.3 \\
\hline$B$ & $56 \mathrm{I}$ & 5. & 1.8 & 2.8 & 2.7 & 2.4 & 2.0 & 1.5 \\
\hline MOEM & 621 & 6.2 & 1,4 & 1.7 & 1.4 & 1.0 & 1.0 & 1.1 \\
\hline DRI 74 & $6 \mathrm{II}$ & 4. & 1.3 & 2.7 & 2.2 & 2.0 & 1.7 & 1.7 \\
\hline st. 1 & 621 & 4. & 0 & 0.5 & -0.2 & -0.2 & -0.2 & -0.2 \\
\hline MPS & & & 1. & 2.2 & 2.2 & 0.7 & -0.5 & \\
\hline W & $65 I$ & 4.6 & 1.3 & 2.0 & 2.4 & 2.6 & 2.4 & 1.9 \\
\hline \multirow{3}{*}{\multicolumn{3}{|c|}{$\begin{array}{l}\text { Mean (w/o St.L) } \\
\text { st. dev. (w/o St.L) } \\
\text { s.d./mean }\end{array}$}} & 1.35 & 2.17 & 2.18 & 1.75 & 1.37 & 1.17 \\
\hline & & & 0.24 & 0.36 & 0.43 & 0.76 & 1.0 & 0.86 \\
\hline & & & 0. & 0.17 & 0.20 & 0.43 & & 0.74 \\
\hline \multirow{2}{*}{\multicolumn{3}{|c|}{$\begin{array}{l}\text { Mean }(w / S t . L) \\
\text { st. dev. (w/St.L) }\end{array}$}} & 1.2 & 1.93 & 1.84 & 1.47 & & .97 \\
\hline & & & & & .98 & 1.01 & 1.1 & \\
\hline \multicolumn{3}{|c|}{ s. dmean } & 0.32 & 0.37 & 0.53 & 0.69 & 0.97 & \\
\hline
\end{tabular}

* $I C=$ initial conditions for policy simulation; RMSE = root mean square error for four quarter forecast of real GNP (billions of dollars at 1958 prices) over 196 -1967 period.

The multipliers are reported with and without the St. Louis model multipliers. The latter are based on a reduced-form income equation rather than on a structural model and, particularly in the case of the fiscal multipliers, differ substantially from the multipliers based on the structural models. 
The mean fiscal expenditure multiplier is just over $1-1 / 4$ in the first quarter and builds to $2-1 / 4$ by the end of year two; however, the cumulative multiplier is still over one after five years. While there is considerable consensus about the multipliers through the first three years, the agreement deteriorates sharply. Note that in all cases the multiplier peaks with in three years, generally within four to eight quarters; and cumulative fiscal multipliers fall to zero or below by the fifth quarter for the St. Louis model, by the 12 th to 16 th quarter for the MPS model and by the 24th quarter for the BEA model. But it

TABLE 2

Fiscal Policy - Tax Cut

Mode1

Muttiplier

$\begin{array}{lllll}10 & 40 & 80 & 120 & 160\end{array}$

$\begin{array}{llllll}\text { BEA } & 0.4 & 1.2 & 1.4 & 1.1 & 0.8\end{array}$

$\begin{array}{llllll}\mathrm{B} & 1.0 & 1.6 & 1.6 & 1.6 & 1.5\end{array}$

$\begin{array}{llllll}\text { MQEM } & 0.6 & 1.2 & 1.1 & 1.1 & 1.2\end{array}$

$\begin{array}{llllll}\text { DRI } 74 & 0.9 & 1.3 & 1.2 & 0.9 & 0.6\end{array}$

St.L*

MPS

W

0

$\begin{array}{lllll}0.4 & 1.3 & 2.1 & 2.2 & 1.8\end{array}$

$\begin{array}{lllll}0.5 & 1.2 & 1.7 & 1.9 & 1.6\end{array}$

Mean (w/o St.L)

$\begin{array}{lllll}0.63 & 1.30 & 1.52 & 1.47 & 1.25\end{array}$

St. dev. (w/o St.L)

0.26

0.16

0.37

0.52

0.47

s.d./mean

0.41

0.12

0.24

0.35

0.38

Mean (w/St.L)

St. dev. (w/St.L)

0.54

0.34

1.11

1.30

$0.5]$

0.66

$1.26 \quad 1.07$

0.63

0.46

0.51

$0.58 \quad 0.60$

* Multipliers reported for St. Louis model are based on absence of a tax variable in the model's reduced-form equation for income. 
takes eight to ten years for the cumulative multiplier to reach zero in the Wharton and Michigan models and still longer in the Brookings and DRI models. 2

The tax multipliers are smaller than the expenditure multipliers; they build from an initial mean value of 0.63 to a peak of 1.5 at the end of the second year. In the case of a tax change, there is less consensus in the first quarter, but no deterioration in later quarters. The tax multipliers tend to peak a bit later than the expenditure multipliers, generally between the 8th and 12th quarters, and then decline.

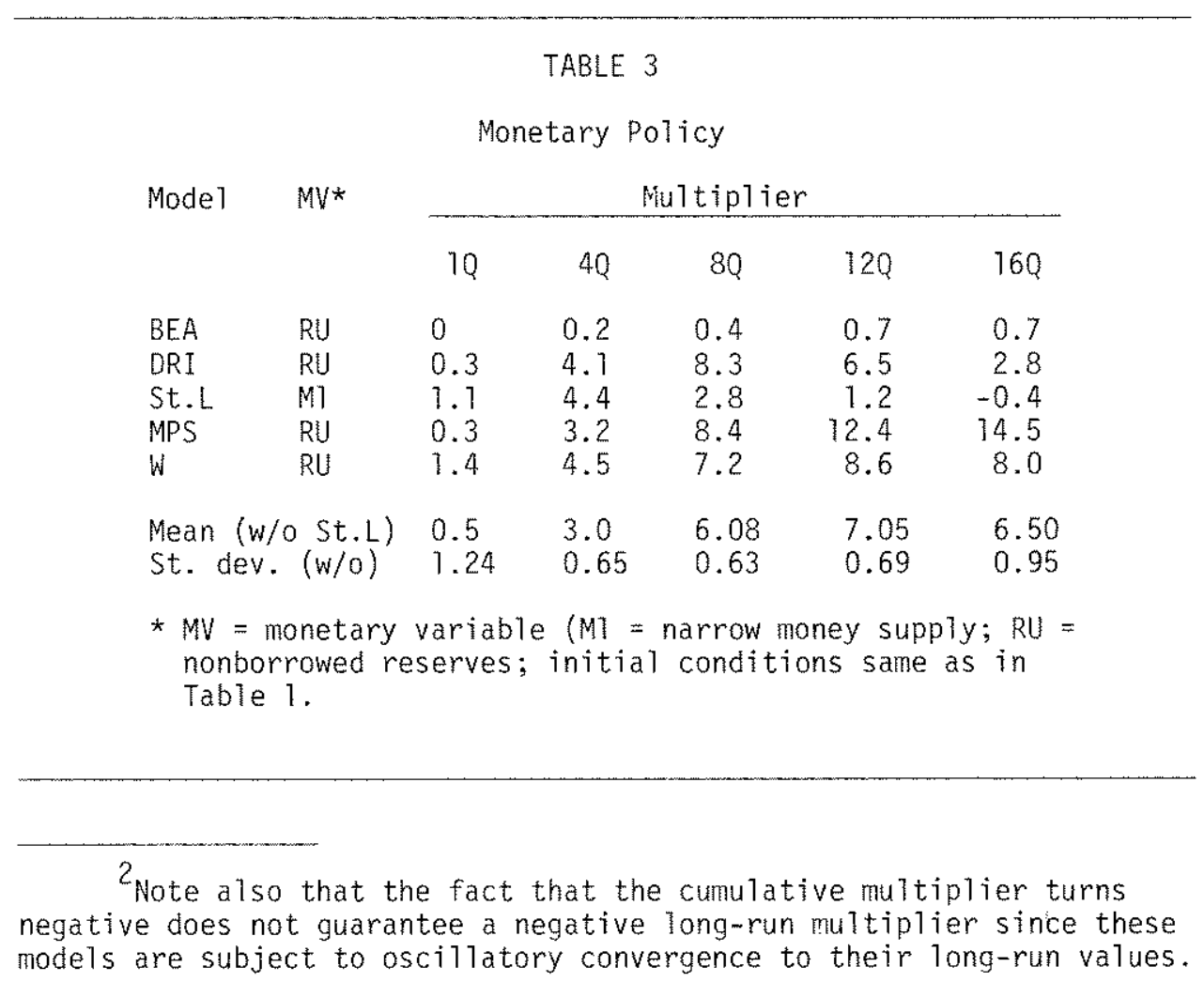


There are only four comparable multipliers for monetary policy (those using nonborrowed reserves). The initiat quarter mean multiplier is small and the mean multiplier peaks at the end of the third year at a value of 7 . There is less consensus about monetary compared to fiscal policy; the coefficient of variation is larger in all but one quarter for monetary policy multipliers. While the St. Louis cumulative multiplier peaks in the fourth quarter and goes to zero by the 16th quarter, large scale model multipliers generally peak after 8 to 12 quarters and the MPS multiplier reported by Fromm and klein is still rising from the 12th to 16 th quarters. The large scale models thus suggest that monetary policy has a more persistent effect on output than is the case in the St. Louis model. The exception is the DRI model in which the cumulative monetary policy multiplier falts to zero by the 20 th quarter.

While the multiplier results do differ across models there is clearly considerable consensus particularly over the first two years in the case of fiscal policy when we exclude the St. Louis results. The problen is evaluating how much divergence in the multipliers is consistent with using the models for policy recommendations. Later we will discuss the use of stochastic simulations which allow for multiplier uncertainty within a particular model. Here we want to note the valuable approach suggested by Chow (1977). Chow notes trat while policy recomnendations derived from alternative structural models differ from each other, they may nevertheless be closer to each other than to a passive policy of constant growth rates in the policy instruments. The comparison chow suggests and implements is the improvement in economic performance in one modet using optimal policy derived from 
a second model relative to the economic performance under passive policy. Chow uses the multiplier properties of the Wharton and Michigan models to construct reduced-form equations for real and nominal GNP including govermment expenditures and nonborrowed reserves as the policy instruments and employs a conventional quadratic loss function involving deviations in real and nominal GNp from their targets (in each case average historical values over the period in question). The results of this experiment are mixed. If the Michigan model were the true structure and the policy recommendations were derived from the Wharton model, active policy would improve performance relative to a passive policy; costs under the active policy would be under 25 percent of those under a passive policy although they would be 70 percent greater than if the policy were derived using the true structure. On the other hand, if the Wharton model were the true structure and the policy recommendations were derived from the Michigan model, the cost under an active poticy would be three times the cost of a passive policy and about 17 times the cost when the true model was used. And, of course, the Michigan and Wharton multipliers are quite close at least for fiscal policies, compared to say the Brookings and the St. Louis models. Thus there are other comparisons that would lead to even less favorable results for activism.

\section{A Comparison of Policy Multipliers Over Time}

We expected to find a secular decline in the value of fiscal multipliers and a secular rise in monetary policy multipliers for large scale econometric models from the late ' 60 s versions to the versions of the mid-to late 70 s. However, published information on such 
multipliers is relatively scarce and what is available is frequently not constructed on a comparable basis. This, of course, increases the value of the NBER/NSF model comparison studies but makes multiptier comparisons pieced together from the literature hazardous. Perhaps the most serious problems for conparing multipliers across models or over time are differences in initial conditions and differences in the specification of policy instruments, particularly for monetary policy. The large scale models are invariably nonlinear, implying that their multipliers are sensitive to initial conditions, particularly the degree of economic slack. But there is painfully little reported evidence of the degree of this sensitivity. There are a bewildering number of possibilities for a change in tax rates and even differences in multipliers for different government expenditure components. The most serious problem, however, may be differences in assumptions about the monetary policy instrument. Monetary policy, particularly in the late 60 s versions, has been identified with changes in short-term interest rates. In other cases, monetary policy is identified with either the money supply or some reserve aggregate, most of ten nonborrowed reserves. The choice affects both monetary and fiscal multipliers since fiscal multipliers assume unchanged monetary policy; fiscal multipliers will, of course, be much larger under fixed short-term interest rates than under fixed values of the money supply or nonborrowed reserves.

In Tables 4 and 5 we have pieced together some policy multipliers for alternative versions of Michigan, Wharton, and MPS models. The Michigan ' 70 and Wharton ' 68 models assume constant short-term interest rates while the others assume constant unborrowed reserves. It is surprising (to us at least) that the fiscal multipliers in the late '60s 


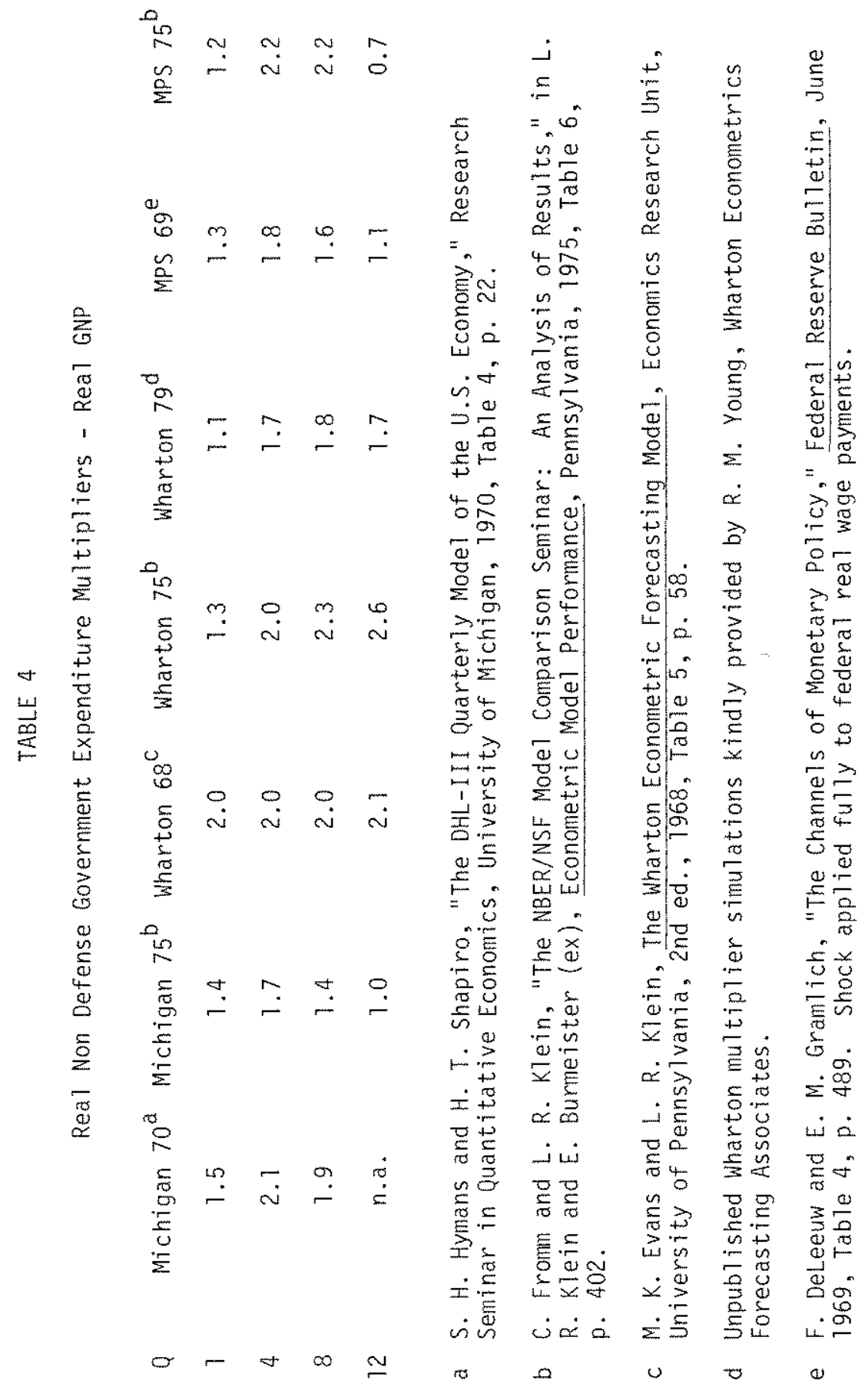

$-49-$ 
versions of the three models (including the two with constant shortterm rates) are so sma17; they peak at 2.0 or less. One important difference in the later versions of Michigan and MPS models is the sharp decline in the cumulative multiplier from its peak value by the 12th quarter. There was a tendency in earlier versions for multipliers to stabilize at about 1.5-2.0 for a longer period. This continues to be the case in the Wharton model; in both the 75 and 79 versions the fiscal multipliers are stable or rising during the first three years. We have been able to find comparable unborrowed reserves multipliers at different points in time for only two models: the Wharton model and the MPS model. These are reported in Table 5 . In these models there is a fairly dramatic evolution of the monetary policy multiplier. In the 1968 wharton model the unborrowed reserves multiplier for real GNP reached a fairly constant level in the 1.5 to 2.0 range after about one year. In the MPS model the multiplier is stable in the 10.0 range during the second and third years. In the later

TABLE 5

Unborrowed Reserve Muttipliers

(ReaT GNP/Nominal Reserves)

\begin{tabular}{lccccc} 
& Wharton $68^{\mathrm{c}}$ & Wharton $75^{\mathrm{b}}$ & Wharton $79^{\mathrm{d}}$ & MPS $69^{\mathrm{e}}$ & MPS $75^{\mathrm{b}}$ \\
1 & 0.0 & 1.4 & 1.2 & 0.7 & 0.3 \\
4 & 1.5 & 4.5 & 4.8 & 5.4 & 3.2 \\
8 & 2.1 & 7.2 & 9.3 & 10.0 & 8.4 \\
12 & 1.7 & 8.6 & 13.3 & 12.4 & 9.4 \\
\multicolumn{2}{l}{ Notes - See Table 4. }
\end{tabular}


lersions of both models, the multiplier is continualy growing over the first three years. Note also the substantial increase in the size of the monetary policy nuttipliers in the Wharton model from the '68 version to the '75 and '79 versions. We view the wharton' 68 multipliers as fairly typical of the conventional wisdom of the mid- to late '60s, prior to the development of the MPS model.

COMMENTS ON THE "ST. LOUIS" EQUATION

Since the original Andersen-Jordan article (1968) (AJ) that proposed a single equation test of the relative importance of monetary and fiscal policies on nominal GNP, numerous replications have been performed, across time, across countries, and across functional forms and a number of criticisms, mostly statistical in nature, have been levied against the equation. The purpose of this section is to review the criticisms that have been raised against the equation and to evaluate how robust the equation appears to be against these criticisms.

The conclusions of the Andersen-Jordan investigation are by now almost universally known. The conclusion that remains most controversial is the zero cumulative fiscal multiplier for nominal GNP. This conclusion did not conform well to the conventional wisdom of the late 1960s, nor was it consistent with other econometric results. Consequently, for the past decade there has been considerable skepticism of the specification that yields this conclusion.

Time Periods, Functional Forms, and Distributed Lags

The AJ equation was estimated over the period $52 / I-68 /$ II and subsequently reestimated by Andersen and Carlson (1970) (AC) over the 53/I-69/IV period as part of the St. Louis model. In each case 
monetary policy had a powerful and significant effect while the tax variable (change in high employment receipts) was insignificant and excluded from their preferred regression and the government expenditure variable had only a small and transitory effect. Silber (1971) subsequently split the period into Republican (53/I-60/IV) and Democratic (6I/I-69/IV) administrations and found that fiscal variables were significant in the latter but not in the former. Sitber argued that these results are consistent with the more systematic use of fiscal policy in the latter period. At a minimum, these results suggest that the time period used in the estimation can dramatically affect the conclusions and that the estimates may reflect the particular policjes pursued over the estimation period.

More recently Friedman (1977) has extended the sample period employed by $A C$ through 76/II and concluded that "even the St. Louts equation now believes in fiscal policy." In Table 6 we report the results of the $A d$ and $A C$ equations along with estimates over alternate time periods including Silber's two subperiods (S1 and S2), Friedman's extended period (F), and the period 1960/I-1976/II (MR). The results suggest that both money and the time period matter: The size and significance of fiscal policy multipliers is not definitely settled by these results.

In response to Friedman, Carlson (1978) has pointed out that the first difference form of the estinated equation, while appropriate over the AC period, is not appropriate over the longer period because of heteroskedasticity, implying that the $t$ values of coefficients reported by Friedman are unreliable. When all variables are defined as rates of change, Carlson finds that the results of the two periods are 


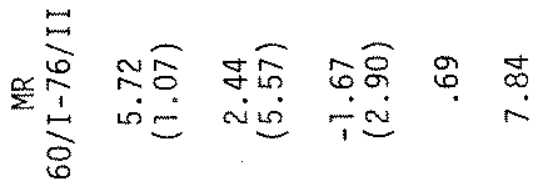

$$
\begin{aligned}
& \text { 慞 }
\end{aligned}
$$

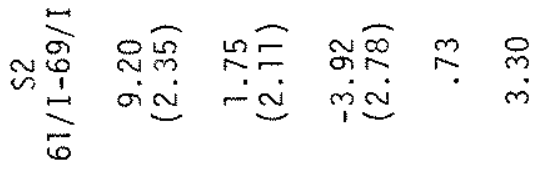

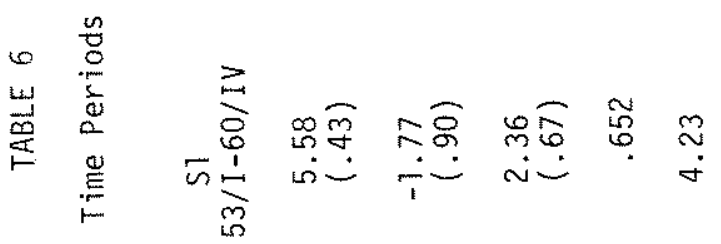

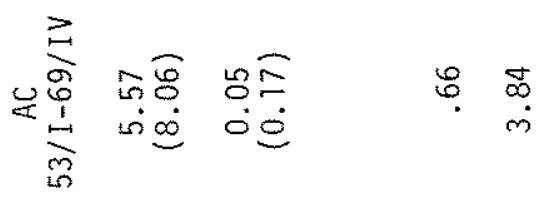

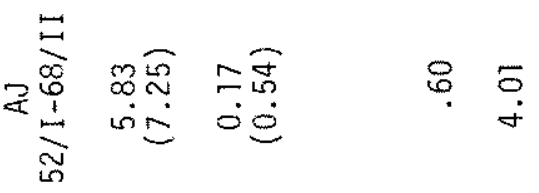

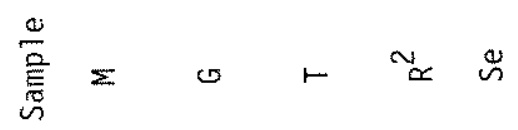


consistent with the hypothesis that the specification is stable and, like the original $A C$ equation, indicate that any effect of government expenditures is sma11 and temporary. Allen and Seaks (1979), using the growth rate specification, find that the fiscal variable sums to zero in both Silber subperiods (Eisenhower and Kennedy-Johnson) but is significant in the Nixon-Ford era (69/II-77/I). Over the period 60/I-76/II we find that both expenditure and tax variables enter significantly into both first difference and rate of change specifications. In Table 7 we report the results of the $A C$ equation in difference form over both the original period (AC) and over Friedman's extended period ( $F$ ) and in rate of change form over Friedman's extended period (C) along with the Allen-Seaks results over the Nixon-Ford period (AS) and both functional forms over the 1960/I-76/II period (MR1 and MR2). From these results we can conclude that money, time period, and functional form matter.

The results of $A J$ type equations are estimated using polynomial distributed lags. This technique requires selection of lag length, degree of polynomial, and end point constraints. Schmidt and Waud (1973) caution that introduction of inappropriate constraints can result in biased and inconsistent estimates and demonstrate how changes in degree of polynomial and end point constraints can substantially alter the conclusions about policy multipliers. Others have found length of lag can affect conclusions also.

We can conclude, therefore, that the choice of time period, functional form, and lag constraints matters a great dea1. The resuTts for money appear very robust. The results for fiscal policy are dramatically affected by these factors. 


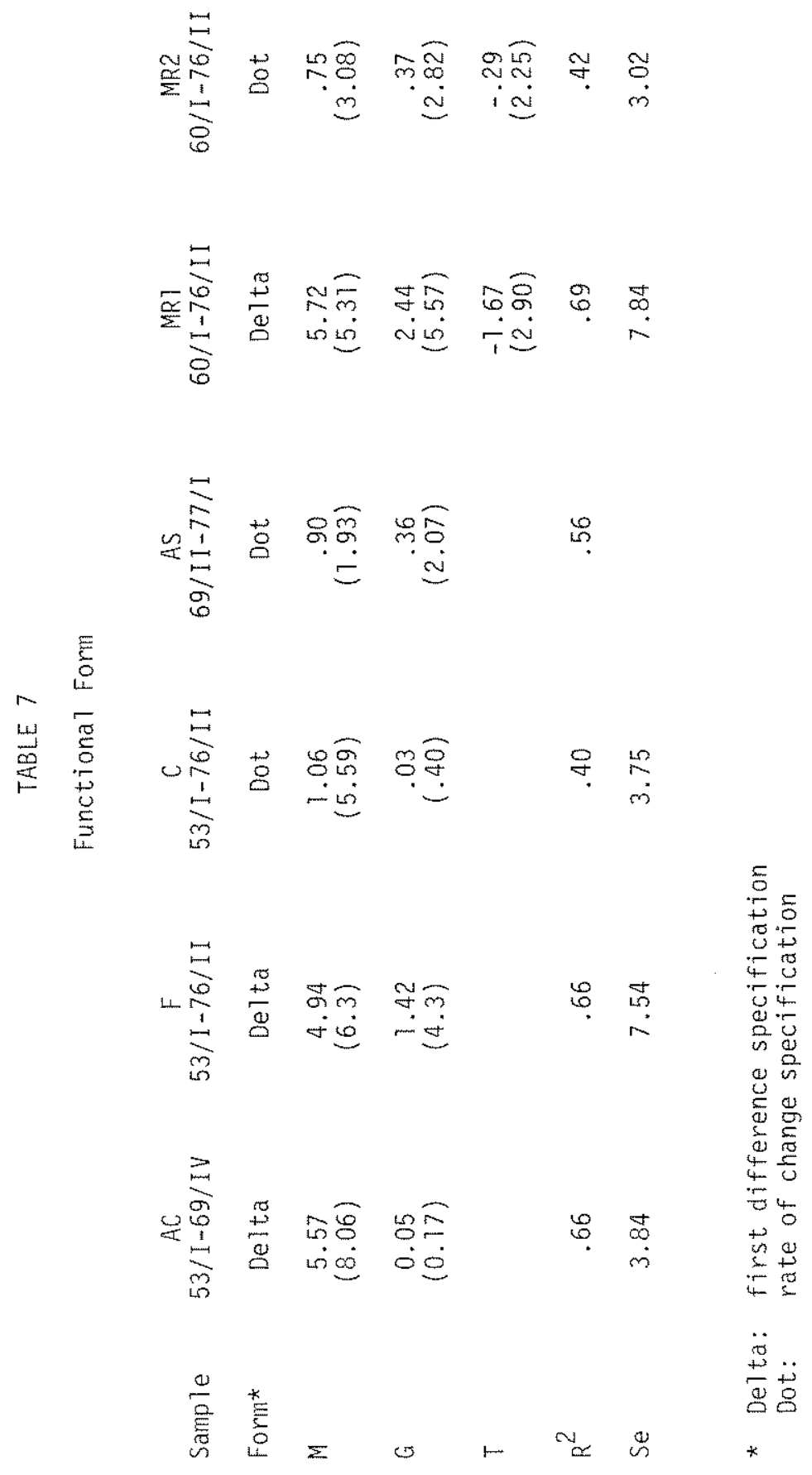


Biases Associated with Choices of Independent Variables

The inconsistency between the $A J / A C$ reduced-form multipliers and the multipliers in large-scale econometric models generated a search (on both sides of the controversy) for an explanation. Monetarists criticized large-scale econometric models for failing to capture the crowding-out phenomenon through misspecification of the money demand equation (e.g. excluding a wealth effect) and failure to explicitly include a government financing constraint. The income expenditure counterattack focused on the unreliability of reduced-forms due to a variety of problems, some more easily correctable than others, associated with the choice of independent variables. The key issues have been: What are appropriate measures of the policy instruments? How can the possibility of reverse causation be avoided? What biases are introduced by omission of nonpolicy exogenous variables?

The Measurement of Policy Instruments

There are two interrelated problems with specifying the policy instruments. The first is the problem of specifying the instrument that the policy authority directly controls. For example, if the fed sets policy by controlling the value of the monetary base, employing a monetary aggregate other than the monetary base as a proxy for the policy instrument may bias the policy multipliers if the other aggregate varies endogenously relative to the base. A second problem arises even if the instruments themselves are included if policy itself systematically responds to economic developments. In this case, the policy instruments themselves become endogenous and reverse causation again may bias the multiplier results. In this section we take up the 
problem of specifying the policy instruments and in the next the problem of endogeneity of policy.

The problem of reverse causation was noted in a DeLeeuwKalchbrenner (1969) comment on the AJ paper. Indeed it was the concern over this issue that arose out of the Friedman-Meiselman debates that motivated the choice of the high employment fiscal policy measures by Andersen and Jordan. Deleeuw and Kalchbrenner ${ }^{3}$ s main concern is with the choice of the monetary base or money supply as the variable the Fed directly controls. They point out that the choice among the monetary base, the nonborrowed base, total reserves, and nonborrowed reserves depends on whether the Fed offsets the effect of movements in member bank borrowing on the base and of movements in currency holdings on reserves. They express no special preference among these alternate measures suggesting only that results which hold for some measures and not for others should be viewed with great caution. Their empirical results indicate that fiscal multipliers are affected by the choice of monetary instrument; in particular, fiscal multipliers of approximately the size produced in the MPS model result when nonborrowed reserves are substituted for the monetary base.

The treatment of fiscal instruments in the AJ/AC equations has also drawn considerable comment. In order to avoid the bias associated with the income induced movements in tax revenues and expenditures (mostly transfer payments) under preexisting schedules of tax and transfer rates, the $A J / A C$ equations use high employment expenditures. High employment receipts were tried but dropped from the preferred equation due to lack of significance. The high employment surplus was also employed in an alternate specification. 
The latter is clearly ar inappropriate measure of stimulus associated with fiscal actions because it groups components which are expected to have different multiplier responses. The same problem arises even in the case of high employment expenditures because this variable includes both expenditures on goods and services and transfers while economic theory suggests that transfers should be netted against taxes. Suggestions for improved specification of fiscal variables have been made by DeLeeuw-Kalchbrenner (DK), Gramlich (1971), and Corrigan (1970). Gramlich employs government purchases of goods and services rather than high employment expenditures, and assumes no adjustment is necessary to purge it of effects of changes in income. Government expenditures are employed in a composite variable including grants-in-aid and exports with an adjustment introduced for defense inventory accumulation.

Deleeuw and Kalchbrenner suggest adjusting high employment receipts to purge changes in this variable of the effects of endogenous movenents in prices. Gramlich uses high employment net tax revenues (taxes minus transfers) also adjusted along 1 jnes suggested by DK. The difficulty with all these series for tax revenues is that the series for changes include nonzero entries in periods during which no changes in tax rates or transfer programs occurred. Corrigan has suggested an alternate tax variable, the initial stimulus measure, that indicates the tax revenues released or absorbed by tax rate changes. This series has plenty of zeros: For each tax, the inftial stinulus measure is the change in tax rates times the lagged tax base. An unweighted sum for all taxes is the variable corrigan used and it continues to be used in the New York Fed version of the St. Louis equation. 
The discussion above suggests that the simple specification of both monetary and fiscal instruments employed in the $A J$ and $A C$ equam tions may be improved upon and that such improvements might alter the relative importance of monetary and fiscal multipliers. However, the modifications suggested above have not generally resulted in dramatic changes in the estimated multipliers in simple reduced-form equations. While many of these suggestions seem valid, they have not helped to resolve the differences between the St. Louis equation and econonetric models.

Endogeneity of Policy

Even if we obtain measures of direct policy actions, our estimates of their effects will be biased if these actions themselves are systematically related to economic developments. This problem has widely been noted in comments on the AJ equation, but most critics including DeLeeuw and Kalchbrenner considered the problems in measuring the instruments the more likely source of bias. The biases associated with endogenous policy are easy to illustrate. If a policy instrument varies in response to disturbances so as to eliminate completely the instability in income, the regression of the change in the policy variable on changes in income (zero by assumption) wil1 yield a zero coefficient on the policy instrument. Thus, endogeneity of policy may result in a downward bias in the policy multiplier, with the downward bias a funcion of the effectiveness of policy. We can, therefore, interpret the zero multiplier on fiscal instruments as evidence of their effectiveness rather than of their insignificance! While the endogeneity of policy may introduce biases into the estimates of policy 
multipliers from both reduced-form equations and structural models, Goldfeld and Blinder (1972) suggest on the bases of simulation results that the bias is much more serious for reduced-forms. If policy responds to economic developments with a lag, the bias is reduced but not eliminated.

Omitted Exogenous Variables

The third major source of bias in the choice of independent variables in the $A J / A C$ equation is alleged to be the omission of nonpolicy exogenous variables. Andersen and Jordan explained in an appendix to their original paper why they believed that the omission of other exogenous variables did not bias their measured impact of the monetary and fiscal policy variables: these variables are presumed to be independent of monetary and fiscal policies and their average effect is registered in the constant term. Modigliani (1971) made the first detailed critique of the St. Louis reduced-form model on the grounds of omitted variables and Modigliani and Ando (1976) reported a more extensive set of simulation results supporting their view that omission of exogenous variables may severely bias the results of reduced forms.

The ingenious simulation experiments involved estimation of an AJ type equation on data generated by non-stochastic simulations of a mode1. The model represents the known structure of a hypothetical economy. The simulated values of nominal income from the model are the "actual" values of income in the hypothetical economy. A reduced-form is estimated using these simulated values for income, and the resulting estimated multipliers are compared with their "true" values (the values implied by the structural model). The comparison of the reduced-form 
multipliers with their "true" (structural model) values tests the ability of simple reduced-forms, including only a couple of policy instruments, to replicate the true value of the policy multipliers.

In the 1971 paper, Modigliani emphasized the finding that the estimate of the St. Louis equation on MPS simulated values yielded a money multiplier in excess of the "true" MPS multiplier and reached the "unequivocal conclusion" that reduced-form money multipliers are upward biased. This bias was attributed to positive correlation between the money supply and omitted exogenous variables. For example, if the Fed attempts to stabilize interest rates (as monetarists assert they often do), then the money supply will be positively correlated with real sector exogenous demand variables and the monetary policy multiplier can be expected to be biased upward.

Modigliani and Ando (1976) turned their attention to biases in the estimates of fiscal effects and suggested that correlation between omitted exogenous variables and fiscal instruments in this case might account for the small size and transitory effects of fiscal instruments in the St. Louis equation. Estimates of the AJ type equation on values of the change in nominal income based on simulations with the MPS model yield fiscal multipliers like the original Ad equation and contrary to the structure of the MPS mode1. They concluded that the St. Louis approach is "a severely biased and quite unreliable method of estimating the response of a complex economy to fiscal and monetary policy actions" (p. 42).

To demonstrate the role of omitted variables in the bias in the AJ equation, they remove any correlation between policy instruments and nonpolicy exogenous variables in the structural models by assuming a 1 
nontrended exogenous variables are constant at their means and a11 trended exogenous variables grow along a constant trend. The predicted value of nominal income for this adjusted structure is computed and used to reestimate the AJ equation. Fiscal multipliers now of appropriate size and magnitude confirm the crucial role of amitted exogenous variables in biasing the estimates of the policy multipliers in the initial Au equation.

In both papers, Modigliani and Modigliani and Ando (MA) are careful to note that the evidence they present does not permit them either to accept the MPS multipliers or reject the St. Louis ones. But their results should make those who use St. Louis type reduced-farm equations uneasy about the validity of the muttiplier results, particularly those for fiscal instruments.

While the analysis demonstrates that omitted variable bias may be a source of serious inferential error in the impact of policy actions, the conclusion appears to be nonconstructive in the sense that it does not provide any evidence on the particular source of the bias in the experiments that were conducted and it suggests abandoning the entire approach without attempting to investigate the issue of biases in the st. Louis results directly. It would be useful to identify the sources of bias in the estimated multipliers by introducing the most important exogenous variables directly into the reduced-form equation.

A number of studies have attempted to address the alleged biases in the St. Louis approach directly by including nonpolicy exogenous variables. Gordon (1976), for example, added a "shock proxy," consisting of the sum of net exports, consumer expenditures on automobiles and non-residential fixed investment to the St. Louis specification. 
Although monetary multipliers decline and fiscal multipliers increase over his longer sample period, the multiplier results with and without the shock proxy remain qualitatively alike; monetary multipliers are significantly positive while the sum of the lag coefficients on the government expenditure variable is not significantly different from zero.

Recently, Dewald and Marchon (1978) have estimated expanded St. Louis equations for six different countries, including the United States. They included exports as a separate independent variable, dismissing the conglomerate variable constructed by Gordon as including too many endogenous influences. For the United States, the Gordon result is replicated; the impact of monetary policy is reduced, the impact of fiscal policy is left essentially unchanged, and the exports variable has a significant contemporaneous impact. A major monetarist contention is that the influence of a mantained change in the monetary growth rate should be a proportional change in the growth rate of nominal income. This hypothesis is alleged to be a universal phenomenon. However, while Dewald and Marchon cannot reject this hypothes is for the U.S. data, the monetary response for the U.S. is the strongest of any of the six countries investigated. The long-run elasticities of nominal GNP with respect to the money stock in the other five countries never exceed .5. In France they found this elasticity to be only .07 and in two countries (France and the U.K.) this estimated elasticity is not significantly different from zero. 
Resolving the Puzzle: Reduced-Form Versus Structural Model Multipliers

Two further tests by Modigliani (1977) attempt to resolve the puzzle of conflicting multiplier results. First of a11, he suggests that despite the apparent large differences in the AC and MPS multipliers, the two sets of multipliers may not be significantly different: To test for significance of the difference in multipliers, Modigliani presumes that the MPS multipliers are the true ones and tests whether the AC multipliers differ significantly from the MPS multipliers. The result is that they are not significantly different at the 5.0 percent level. Modigijani concludes, "This test resolves the puzzle by showing that there is really no puzzle: the two alternative estimates of the expenditure muttipliers are not inconsistent, given the margin of error of the estimates. It implies that one should accept whichever of two estimates is produced by a more reliable and stable method, and is generally more sensible. To me, these criteria call, without question, for adopting the econometric model estimates." (p. 10)

For those who would still opt for the reduced-form multipliers, Modigliani compares the post-sample prediction performance of the AC equation with one in which the coefficients of government expenditures plus exports were constrained to equal those based on multipliers derived from simulations with the MPS models. The post sample simulation begins in 1970II. For the first four years, the MPS based equation dominates: the AC equation yields "distinctly larger" errors in eight quarters, smaller errors in only three quarters, and results in a squared error 1/3 larger than for the MPS based equation. Over the next two years, both equations perform "miserably" but the MPS based equation is still "a bit better." 
Conclusion

The income expenditure counterattack on reduced-forms, particularly the Modigliani-Ando results on the implications of omitted exogenous variables, and the ability to dramatically alter the fiscal policy multipliers by choice of time period and functional form, have substantially weakened the case based on reduced-form equations for small and transitory fiscal effects on nominal income. The implied monetary policy multipliers, on the other hand, have proven robust, at least for the United States.

ASSESSING THE CUMULATIVE OUTPUT LOSS OF ERADICATING INFLATION A prominent policy issue of the 170 s and one that seems certain to dominate at least the early ' 80 s is the appropriate policy response to a prevailing high rate of inflation. The view that there is a longrun trade-off between inflation and unemployment, widely held at the end of the 60 s, is now held by only a small minority. The key issues are the nature of the short-run relation between inflation and unemployment and the process by which economic agents form inflation expectations. Macroeconomic models, both income expenditure and monetarist versions, suggest that while the traditional demand management techniques remain quite capable of reducing the rate of inflation, the cost of such a policy in terms of cumulative output loss would be great. Despite the importance of the issues, there is substantial disagreement about the cost of eradicating inflation and little evidence on the benefits derived as a consequence.

In this section we present evidence on the cumulative output loss associated with reducing inflation based on both estimated Phillips 
curves and monetarist models. Then we discuss the most serious 1 imitation of these results - the fallure to allow the results to be influenced by the degree to which the public believes policy authorities are comitted to a consistent anti-inflation policy, In the final analysis, the cost of anti-inflation policies in the form of output loss must be balanced against the benefits associated with a reduced rate of infiation. Empirical evidence on the cost of inflation and hence the benefits of reducing inflation is quite limited. Our discussion of the benefits of anti-inflation policies is therefore confined to determining how large the per period gains would have to be in order to justify incurring the cumulative output loss which we calculated from the phillips curves and monetarist models.

\section{Econometric Evidence on the Size of the Cumulative output Loss}

Three alternative sources of evidence on the cumulative output loss associated with the use of demand management policies to moderate inflation are discussed below. The first is evidence directly from estimated Philips curves. Here we calculate how long unemployment must be increased by either 1 percentage point or 3 percentage points above the rate consistent with steady inflation to reduce inflation by 7.5 percentage points. The second and third sources use monetarist models which include either a Phillips curve or a reduced-form equation relating inflation to monetary change. Here we simulate the effects on inflation and output of a phased deceleration in monetary growth.

Results Based on Estimated Phillips Curves

Three recent studies have considered the cost of reducing inflation in the context of traditional Phillips curve regressions (Perry 
(1978), Okun (1978), and Cagan (1978)). Perry's results are based on a wage change equation using the inverse of his weighted unemployment rate and lagged wage change estimated using annual observations over the 1954-77 period. His preferred equation yielded a "nonaccelerating inflation rate of employment" (NAIRU) of 4.0 in terms of his weighted unemployment rate (corresponding to about 5.5 percent in the official unemployment rate in ${ }^{\prime} 77$ ):

$$
\begin{aligned}
\Delta \ln W= & -1.88+7.44\left(1 /(\mathrm{W})+0.79 \Delta 1 \mathrm{nW}-1+0.21 \Delta 1 \mathrm{nW}_{-2}+1.07\right. \text { DNIX } \\
& (-2.2)(3.5)(1.1) \\
& \text { S.E. }=0.70
\end{aligned}
$$

where $W$ = adjusted hourly earnings in the private nonfarm sector and DNIX is a dummy for the controls equal to -7 in 1972 and 1973 and +1 in 1974 and 7975 .

Any unemployment rate in excess of the critical unemployment rate, if maintained long enough, will permit a cycling down of inflation. To compute the cumulative output loss of eradicating inflation, we begin with $\Delta \mathrm{n} W$ set equal to 10.0 in the two lagged years and at NAIRU, Our "moderate" policy consists of increasing the weighted unemployment rate 1.0 point above NAIRU in period 1 and holding it here until sin $W$ declines to 2.5 , the rate presumed equal to trend growth in Tabor productivity and, therefore, consistent with price stability. The wage inflation rate falls from 10.0 to 9.6 percent in the first year and declines about 0.3 percentage points per year thereafter taking 23 years to reach a 2.5 percent rate. An alternative "radical" policy is modeled as a 3 percent point increase in unemployment beginning in period one and again sustained until wage change declines to

$$
-67-
$$


2.5 percent. This takes only 11 years! Note that the nonlinearity in Perry's wage equation ensures that the cumulative excess of person years of unemployment and, hence, cumulative output loss will be greater in the more radical policy case.

Using Okun's estimate of 3.2 as the impact on output of a 1 percent point increase in unemployment, we can convert the excess unemployment into output loss. ${ }^{3}$ One percentage point increase in unempioyment reduces output 3.2 percent or $\$ 45.6$ bi1lion dollars (calculated at 1978 value for real potential GNP). The 3 percent point increase in unemployment involves an initial year output loss of $\$ 136.7$ billion. To find the cumulative, but undiscounted output loss we assume potential output will rise at a 3.3 percent rate. This yields a cumulative loss of $\$ 1532.6$ billion for the moderate policy and $\$ 1778.0$ billion for the radical policy. ${ }^{4}$ The discounted output loss is essentially the product of the initial year loss and the number of years required to complete the program (not accounting for the 3.3 percent rate of growth in potential output is the same as discounting by a 3.3 percent rate); the discounted losses are $\$ 1047.9$ billion and $\$ 1503.6$ billion in the modest and radical cases, respectively. The results are depicted in Charts 1 and 2. (Perry 1 refers to the moderate case and Perry 2 to the radical case.)

3 Estimation of the Okun law relation over more recent data suggests that 3.2 may be an overestimate of the output loss associated with a one percentage point increase in unemployment; the recent estimates are about 2.5 .

${ }^{4}$ If the Okun's law coefficient is 2.5 instead of 3.2 , these output losses should be reduced by about 20 percent.

$-68$ 


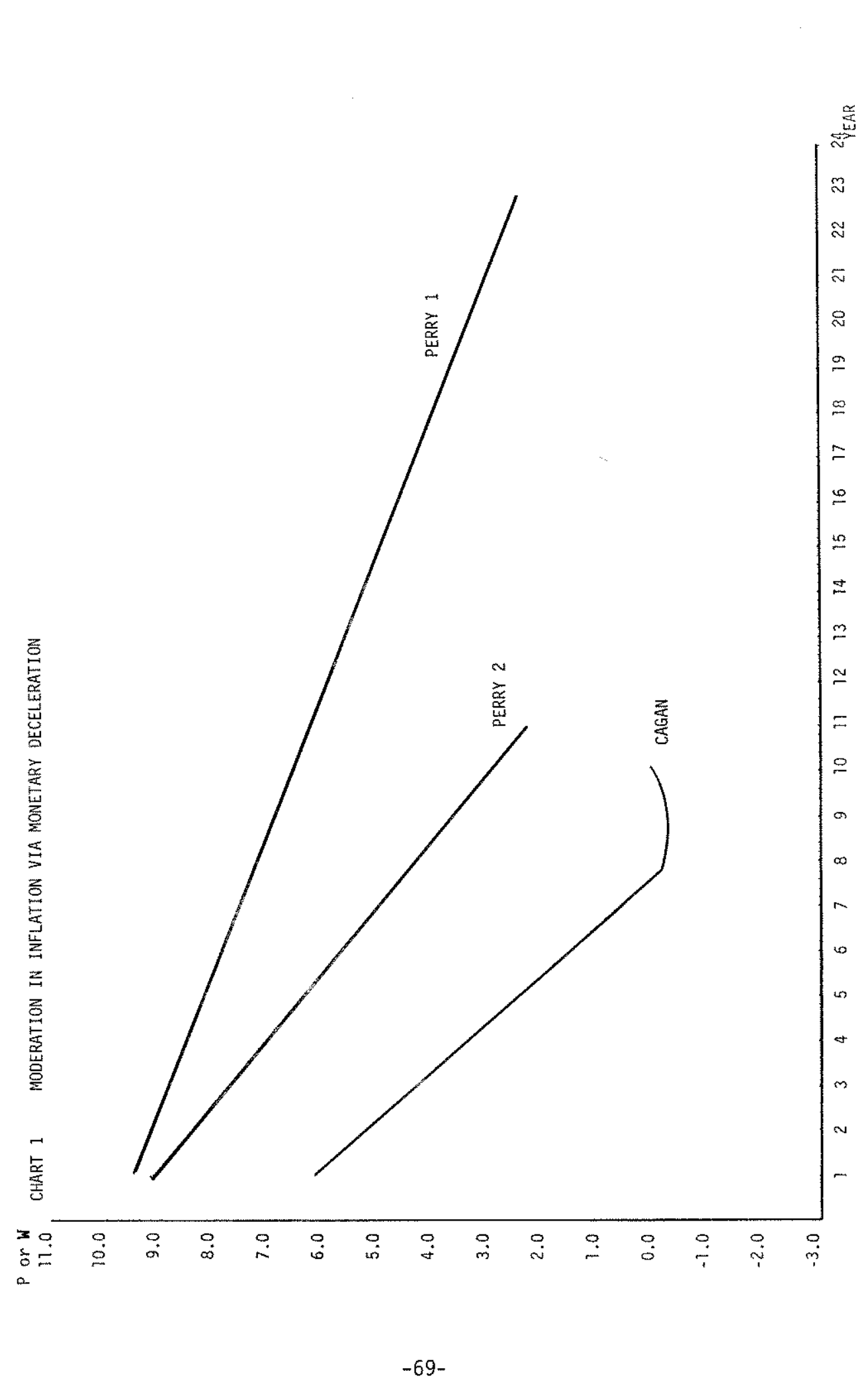


Okun finds that a variety of estimated Phillips curves (PCs) in the literature yield quantitatively similar conclusions. The six equations considered by okun yield a first year reduction in inflation of from $1 / 6$ to $1 / 2$ percentage point and an average of 0.3 percentage points for a 1 percentage point increase in unemployment. Gramlich (1979) reached a similar conclusion.

There are two aspects of the Perry specification which deserve further discussion: expectations are formed adaptively and the unemployment rate enters nonlinearly. The phillips curve is uniformly drawn as a nonlinear relation and there have been a number of theoretical explanations (including Lipsey and Tobin) and some empirical support (Perry's influential 1966 study, for example). However, nonlinear and Iinear specifications seem to do about as we1] over sample through the mid-1970s. 5 The existence of nonlinearity would provide a rationale for the gradual as opposed to radical policy approach; the greater the nonlinearity, the greater the cumulative output loss under the radical as opposed gradual policy.

The inflation inertia implicit in the Perry equation derives from two sources: actual inflation is built into expected inflation with a 1 ag and actual inflation responds gradually to unemployment in excess of the critical rate. To the extent that the 1 ag in incorporating actual inflation into future wage negotiations is long, indexation might substantially reduce the inflationary inertia. Even with indexation, there would be a lag. Assuming that the full effect occurs

${ }^{5}$ Cagan (1977) has recent $1 y$ noted the surprising lack of evidence of nonlinearity and this has been confimed in a careful examination by Papademos (1977). 


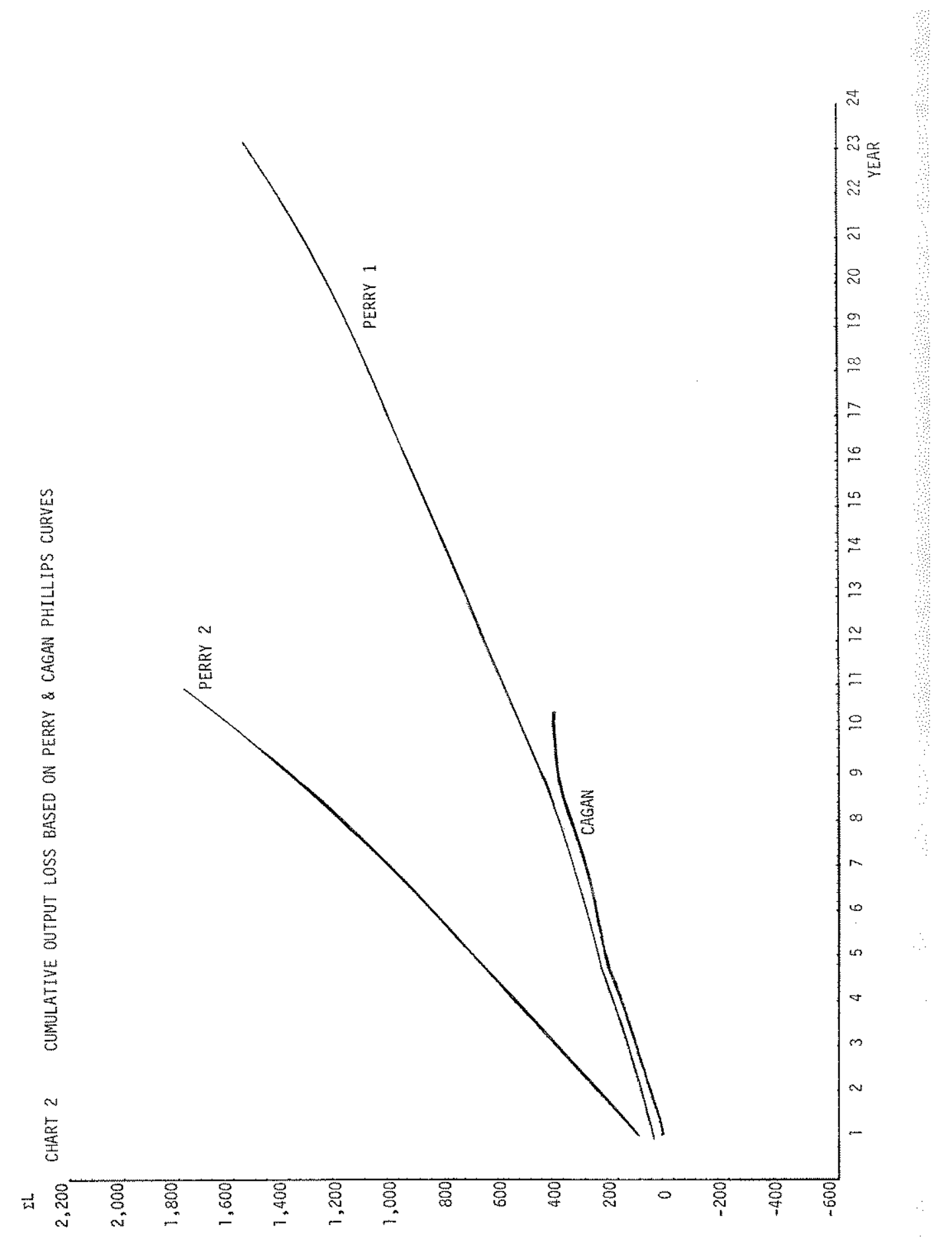

$-71-$ 
within the first year would not dramatically reduce the cumulative output costs. The cumlative output loss would decline about 20 percent in each case. Thus, the critical determinant of the gradual decline in inflation is the extremely small per period deceleration in inflation associated with labor market disequilibrium (excess unemployment) in the conventional phillips curve, not with the slow response of inflation expectations to changes in the actual inflation rate.

Cagan develops a PC equation beginning with the natural rate specification and assuming adaptive expectations Cagan's estimated PC is:

(2) $\dot{p}_{t}=\dot{p}_{t-1}-0.95\left(\frac{u_{t}-u_{t-2}}{2}\right)-0.23\left(\frac{u_{t}+u_{t-1}+u_{t-2}}{3}-\bar{u}\right)$

where $\dot{p}$ is the quarterly rate of change in the CPI, $u$ is the unemployment rate for prime age males and $\bar{u}$ is estimated from the constant of the regression (3.7, for this regression) and the equation is estimated using quarterty observations over the period 1953-1977.

As is clear in Charts 1 and 2, the Cagan equation generates a dramatically more rapid decline in inflation and smaller cumulative output 10ss. Beginning in period 0 at a 7.5 percent inflation rate (in the current and last period) and at NAIRU, a one percentage point increase in the unemployment rate reduces inflation by the full 7.5 percentage points by the eighth year with cumulative output loss of $\$ 4.2 .9$ billion, about a quarter of that associated with the Perry and okun results. 
Evidence Based on the St. Louis Model

To provide additional evidence on the output effects of using stabilization policy to reduce inflation, we ran simulation experiments with the St. Louis model. 6 We begin with a base run in which the rate of monetary growth is at a steady 7.5 percent rate begining in 1968/III through 1978/IV. This builds in inflation inertia and provides the base against which we can evaluate the effects of gradual monetary deceleration. Beginning in 1973/I we gradually decelerate monetary growth by 1 percentage point in the first quarter of each year. We then compare the policy runs with base run and compute the cumulative output loss associated with the policy.

The first set of simulations with the St. Louis model employ the version of the model estimated over the sample period 1953/1-78/IV. The general practice at the Bank is to employ the estimates of the model using all available data for forecasting and policy simulations. The version estimated through $78 / \mathrm{IV}$, however, has a very large coefficient on the demand slack variable in the model's Phillips curve, almost three times the size of the coefficient estimated with data through 71/II or 75/I, for example. The results are reported in charts 3 and 4 by the lines labeled StL1. There is a rapid deceleration in inflation and a low cumulative output 10s5. The inflation rate begins to decline very slowly; it takes two years to reduce the inflation rate by I percentage point. Thereafter the deceleration speeds up so that after

\footnotetext{
${ }^{6}$ For a description of the St. Louis model, see Andersen and Carlson (1970). The model includes a reduced-form equation for nominal income and a Phillips curve equation for price change; output is then solved for via an identity.
} 
5-1/2 years, inflation has declined by 7.5 percentage points. The unemployment rate rises slowly at first and the maximum increase is only 1.8 percentage points, during the sixth year. The cumulative output loss is only about $\$ 200$ billion.

The output loss is, of course, sensitive to the coefficient on the demand variable in the Phillips curve. Using a version of the model estimated through 7I/III, where the coefficient on the demand variable is substantially smaller than in the first version discussed, inflation decelerates much more gradually; after six years the inflam tion rate in the policy run is only four percentage points below that in the base run. At this point unemployment is four percentage points higher than in the base run. The cumulative output loss is $\$ 350$ billion at this point and escalating rapidly. These results are depicted in Charts 3 and 4 by the lines labeled StL2.

Evidence Based on Reduced-Form Equations

Given reasonable doubt about the validity of the Phillips curve, ${ }^{7}$ it is useful to consider the implications of reduced-form models that are not tied directly to an explicit Phillips curve. We consider two examples: Stein's (1978) two equation model of inflation and unemployment and AJ type equations for nominal income and inflation. The results are depicted in Charts 3 and 4 by the lines labeled Stein (Stein 1 for the moderate case and Stein 2 for the radical case) and StL3.

\footnotetext{
${ }^{7}$ See, for example, Stein (1978).
} 


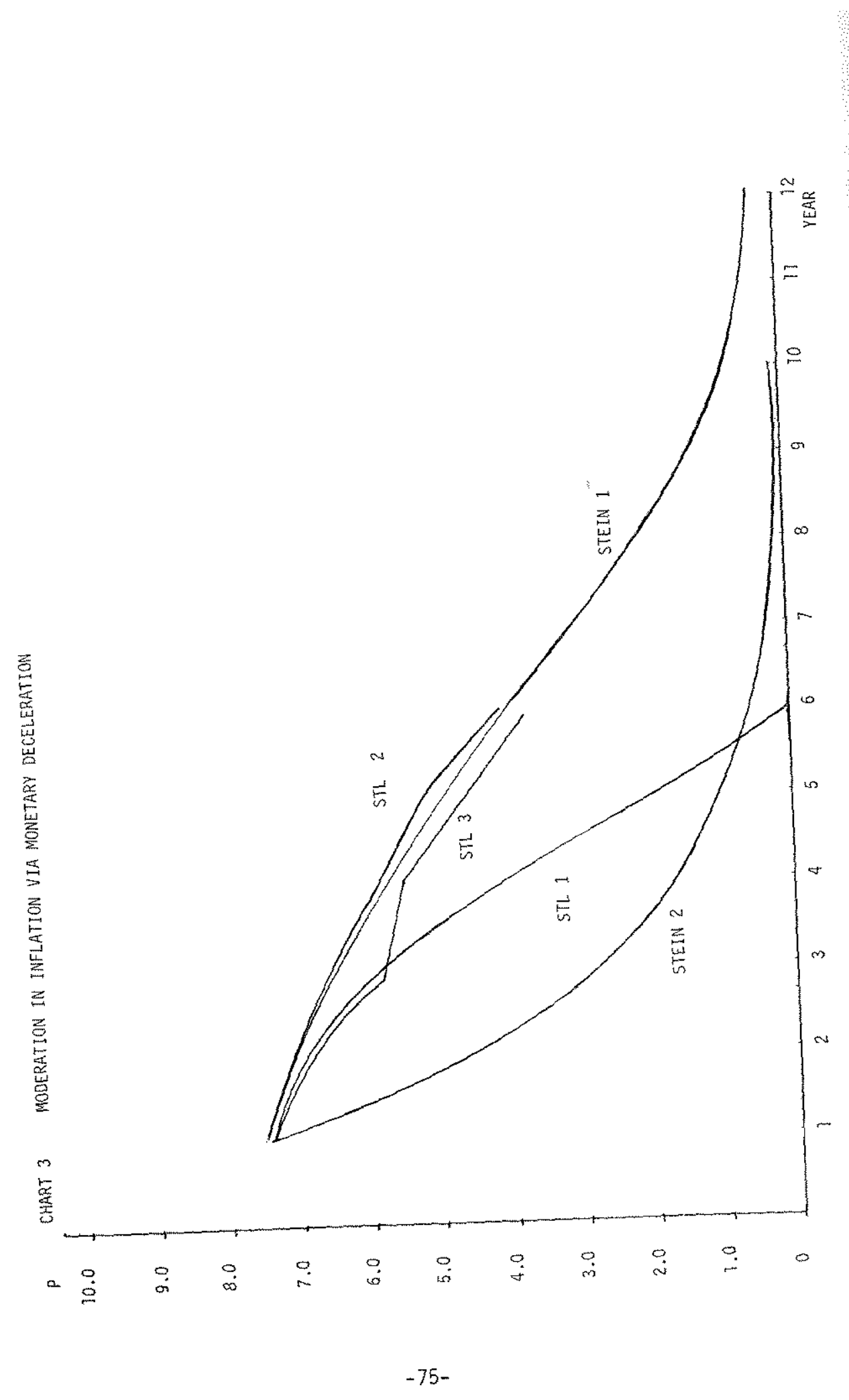


The Stein model $\cdots$ In the Stein model, both unemployment and inflation are driven by the rate of monetary growth. Stein's two equation model is:

(3) $\Delta u(t)=3-0.6 u(t-1)+0.4 \pi(t-1)-0.4 \mu T(t-1)$

(4) $\Delta \pi(t)=-0.4 \pi(t-1)+0.4 \mu(t-1)$

where $u$ is the unemployment rate, $\pi$ is the inflation rate and $\#$ is the rate of monetary growth. The critical unemployment rate is 5.0 and the equilibrium rate of inflation is the rate of monetary growth. Beginning at $u=5.0$ and $\pi(t)=\pi(t-1)=7.5=1.1(t)=\mu_{1}(t-1)$, we decelerate the rate of monetary growth either (a) gradually by 1 percentage point per year unti $1 \ldots=0$ or (b) immediately to 0 . In the gradual policy, unemployment rises beginning in year 2 and peaks in year 8 at 6.6 percent returning to alnost 5 percent by year 16 . The inflation rate begins to decelerate in year 2 initially at a 0.4 percent point a year rate but ultimately reaches 1.0 point per year by year 7 . The inflation rate is down to 2 percent by year 8 and thereafter declines gradually to about zero by year 16 . The cumulative output loss is $\$ 687.5$ billion. Interestingly, the gradual policy incurs a smaller cumulative output loss, $\$ 613$ bil1ion.

The 5t. Louts reduced-form equation for income with a reducedform for inflation -- A second simulation based on reduced-form equations combined the reduced-form for nominal income in the $5 t$. Louis model with a reduced-form equation for inflation. ${ }^{8}$ The inflation

${ }^{8}$ The reduced-form equation for inflation used in this section was developed by Jack Tatom of the Federal Reserve Bank of St. Louis. An earlier version of this equation was used by Tatom in "Does the Stage of the Business Cycle Affect the Inflation Rate?" Federal Reserve Bank of St. Louis Review, September 1978, pp, 7-15. 


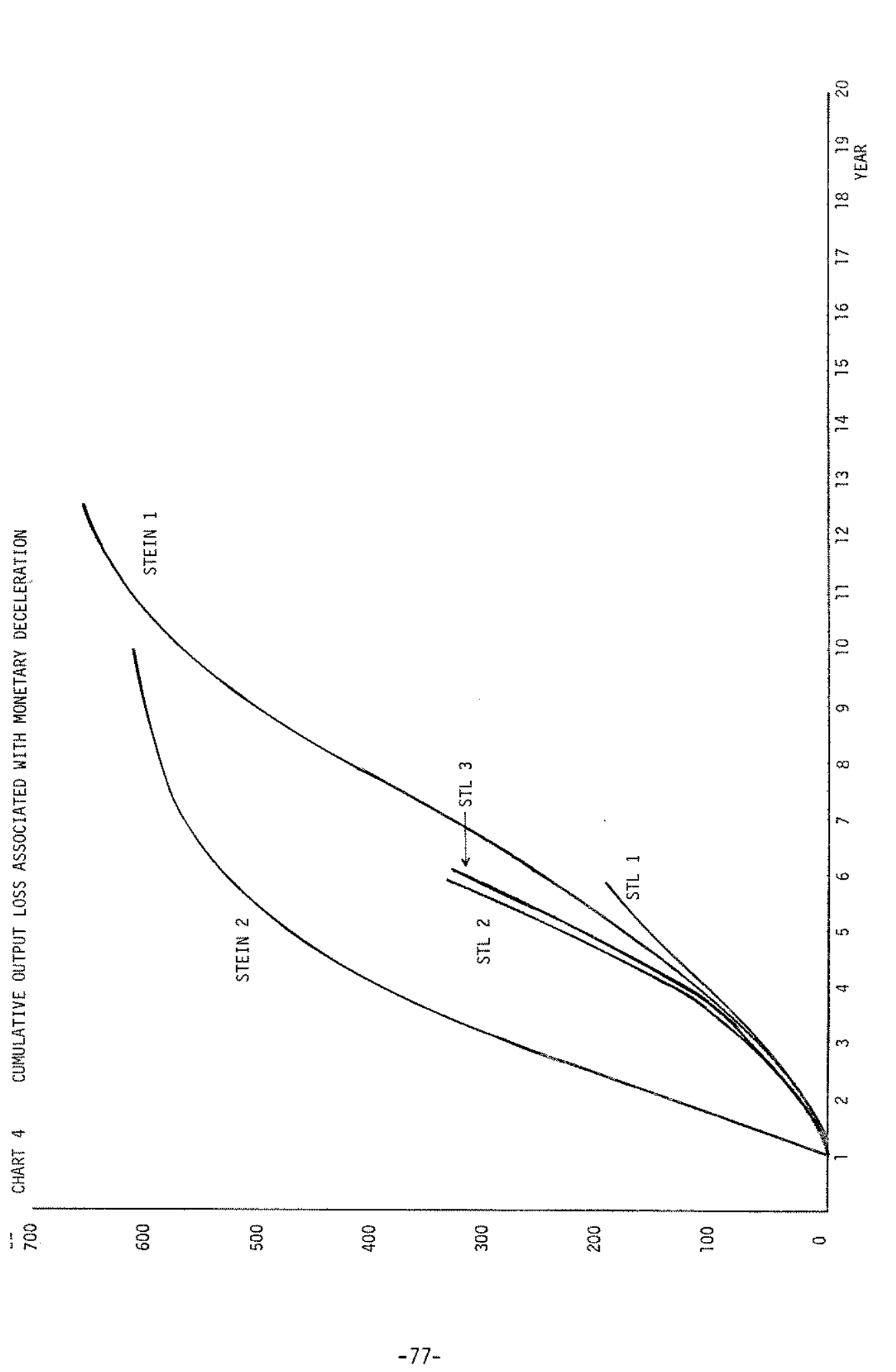


reduced-form includes a twenty period distributed lag on the rate of change in the money supply and a four quarter distributed lag on the differential in the rate of change in producer prices for energy and the price index for the nonfarm business sector, and two dummies for the effects of the freeze and Phase II and for the subsequent catch up effects. The St. Louis equation yields values for nominal income; the inflation reduced form is employed to generate price level predictions; and the price level is used to deflate nominal income to yield real output predictions. The results in charts 3 and 4 depicted by the line labeled StL3, reflect the response to the same phased monetary deceleration employed with the other St. Louis model simulations described above.

Note the similarity with the st. Louis results with a Phillips curve (based on the sample period through 71/111), StL2, in Charts 3 and 4. With the reduced-form equation inflation declines more rapidly, by about $.20-.30$ percentage points per year over most of the period; correspondingly, the output loss is somewhat smaller. But the time pattern and magnitude of both the deceleration in inflation and the cumulative output loss are remarkably similar. Again note that the output loss per quarter has not peaked after sjx years of the phased deceleration so that the cumulative output loss is still rising rapidly at the end of six years.

\section{Qualifications of the Empirical Analys is}

The results reported above are derived both from explicit Phillips curves, and from monetarist reduced-forms. The existence of a cumulative output loss associated with eradicating inflation is 
therefore generally consistent with both income-expenditure structural models and monetarist reduced-forms. The major deficiency of the empirical analyses on which the results described above are based is the fajlure to allow the public's perception of current and future policy to affect expectations about future inflation.

The Credibility Effect

The results reported above based on Phillips curves all related inflation in the current period to a distributed lag on past inflation rates where the latter are intended to reflect the rate of inflation expectations (and/or direct the influence of past inflation as for example via catch-up effects). This specification does not allow the degree of credibility associated with announced anti-inflation policies or even the expected influence of recent policy actions to influence inflation expectations. The estimates of cumulative output loss generated by such models are, therefore, almost certain to be overestimates. Feliner (1979), for example, maintains that $\ldots$ the standard model coefficients... would change significantly for the better - in the direction of a much more rapid rate of reduction of inflation for any given slack -- if a demand management policy... changed to a credible policy of consistent demand disinflation." But by how much does the standard model overestimate inflationary inertia? By 10 percent, 50 percent?

We do not have any reliable quantitative estimate of the degree to which policymakers can speed the deceleration of inflation by clearly defining their anti-inflation policies and convincing the public that they intend to follow through. Nevertheless, there would 
be nearly universal agreement that anti-inflation policies ought to be set out clearly and supported by both the Treasury and the Federal Reserve in such a manner as to maximize the credibility effect.

Rational Expectations and the Cumulative Output Loss

In the extreme form of rational expectations models advocated, for example, by Sargent and Wallace (1976), the cumulative output loss associated with a credible policy of monetary deceleration should be zero. These models have two essential features: 1) they are equilibrium models in which prices respond immediately and fully to monetary change and real variables such as unemployment and output respond only to unanticipated inflation; and 2) inflation expectations are formed rationally, taking into account knowledge both about the structure of the economy and the systematic features of policy.

In such a model, inflation should moderate immediately in response to the monetary deceleration, provided, of course, that the policy was announced in advance and believed (or otherwise expected). We had thought of running simulations with an RE version of the St. Louis model along lines suggested by Andersen (1979). On a moment's reflection, the implications were sufficiently obvious that computer simulations could be dispensed with. The St. Louis model has a Phillips curve in which inflation depends on a demand variable $(x)$ and expected inflation $\left(\dot{p}^{e}\right)$ where the latter is determined from an adaptive expectations model with weights taken from a regression of the nominal interest rate on past inflation rates:

(5) $\dot{p}=\alpha+\beta x+\varepsilon \dot{p}^{e}$ 
Andersen's RE version imposes the condition that $\dot{\mathrm{P}}^{\mathrm{e}}=E(\dot{\mathrm{P}})$; i.e., that subjective inflation expectations equal the model's forecast for inflation. In this case:

(6) $E(\dot{P})=\alpha+\beta X+\varepsilon E(\dot{P})$

(6') $E(\dot{p})=\frac{1}{1-\varepsilon}(\alpha+\beta x)$

and Andersen substitutes

(7) $\dot{p}=\frac{1}{1-\varepsilon}(\alpha+\beta x)$

for the St. Louis Phillips curve.

Andersen sets $\varepsilon=.86$, its value in the $5 t$. Louis model. However, if $E$ is meaningfully viewed in this case as the coefficient on expected inflation, the value of .86 estimated in the St. Louis model should not be accepted as the magnitude of that parameter in the RE version of the St. Louis model because the value of $E$ was estimated under the assumption that expectations were formed adaptively. Taking $E=1$, as seems essential to the RE model, equation 7 no longer is a meaningful equation for $\dot{P}$. Instead we obtain from $(6)$ where $\varepsilon=1$ $\left(6^{2}\right) \quad 0=a+\beta x$

so that there is a unique value of $x^{*}=-\alpha / \beta$ corresponding, of course, to the natural rate of unemployment. $x$ can differ from $x^{*}$ only on account of random disturbances (with zero mean). In this case any effect of monetary deceleration on the rate of growth of nominal income is transformed immediately and fully into a decline in inflation without any cumulative output 10ss. This seems to us a more 
meaningful RE version of the $S t$. Louis model than that employed by Andersen. 9

Balancing the Gains from Reducing Inflation Aga inst the Transitionat Costs 10

The cumulative output loss is a measure of the cost of antiinflation policies. To evaluate the desirability of such policies we also need to assess the gains from reducing inflation. Unfortunately, the costs of inflation (and hence the benefits of reducing inflation) are not as clearcut or easily quantifiable as the cost of unemployment. Fischer and Modigliani (1978) provide a careful outline of the costs of inflation. The costs include the welfare loss associated with the incentive to economize on cash balances, the reduction in capital accumulation due to disincentives for saving and investment that reflect the way in which the tax system permits inflation to affect after-tax

${ }^{9}$ There is a second and related objection to Andersen's approach. In the $5 t$. Louis model $E$ is not the sum of the coefficients on lagged inflation rates. Indeed the sum of the coefficients is generally about 1.0. The reason for this is that the st. Louis phillips curve does not estimate the weights on lagged inflation directly within the estimation of the Phillips curve itself. First, an equation for a short-term interest rate is estimated as a function of the rate of monetary growth and distributed lags on both the rate of change in output and on past inflation rates divided by the ratio of unemployment to the fullemployment rate. The sum of the coefficients on lagged prices from the interest rate equation in the original Andersen/Carlson article was 1.27 so the sum of weights on lagged inflation rates in the phillips curve is $.86\left(1.27 /\left(u / u_{f}\right)\right)$, approximately 1.0 . The sum of the inflam tion coefficients from the interest rate equation vary considerably over different sample periods and the estimate of $\varepsilon$ always compensates to yield a sum on past inflation rates of about 1.0 . This reinforces our view that the value of $\varepsilon$ in equation (6) should be taken as 1.0 .

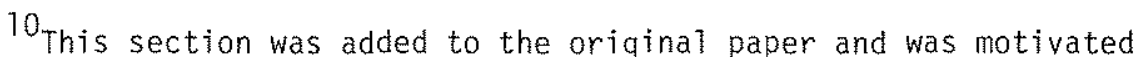
by comments by Jerry Jordan and Allan Meltzer at the conference. 
rates of retum and the cost of capital, and the arbitrary redistribum tion of income and wealth due to unanticipated inflation.

While Fischer and Modigliani do provide estimates of some compom nents of the costs of inflation, neither their study nor others permit us to compute a meaningful estimate of the benefits that would accrue from reducing inflation which could in turn be compared with the cost in terms of cumulative output loss. What we can compute is the minimum size of the permanent gain in output per year due to eradicating inflation which would just justify incurring the cuntative output loss associated with the transition to price stability. We will refer to the benefits as a gain in real output per year. Some components of the gain may, however, be welfare or utility gains that would not necessarily show up in computed measures of real output. While such welfare gains are even more difficult to evaluate than output gains, they are no less important in developing a measure of the benefits of reducing inflation.

Figure $I$ depicts the comparison we wish to make. The dashed $X$ Tine is the rate of growth of (potential) output if inflation remains

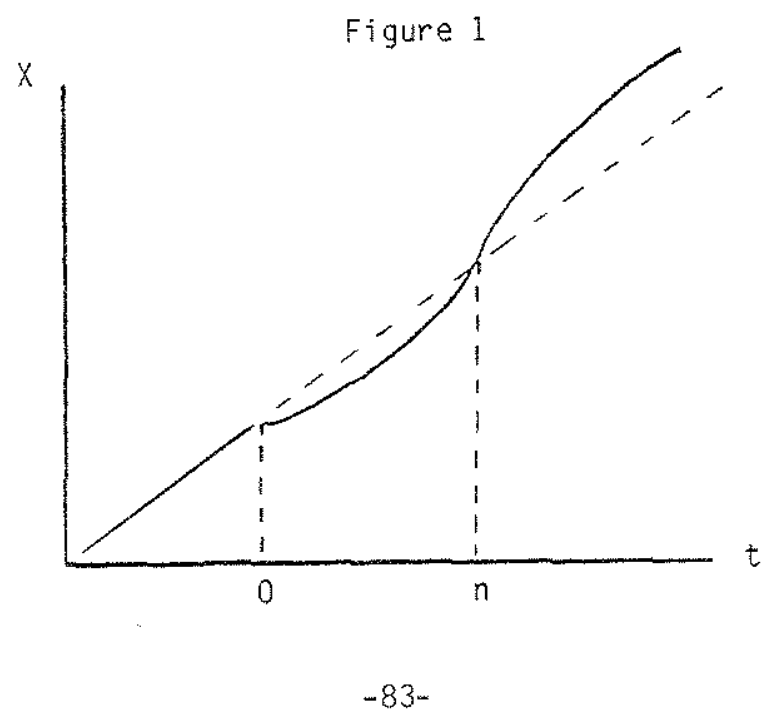


indefinitely at 7.5 percent. If anti-inflation policjes are pursued, output is assumed to follow the solid line. The transitional costs occur between $t=0$ and $t=n$ as unemployment rises above the rate associated with potential output. However, if there are costs of inflation, output will rise above the level that would have prevailed if the initial steady inflation rate had continued. We define $G$ as the present value of the permanent per period output gain, evaluated from period $n$ to $\infty$.

(8) $G=\sum_{i=n}^{\infty} \frac{g_{i}}{(1+r)^{j}}$

This can be compared to the present value of the cumulative output loss (L)

(9) $L=\sum_{i=0}^{n-1} \frac{L_{i}}{(1+r)^{i}}$

where $L_{i}$ is the output loss in the $i$ th period $(i=0, \ldots n-1)$.

Assuming that the unemployment rate is maintained above the rate consistent with potential output by a fixed amount for $n$ periods, the loss in period $i$ can be expressed as

(10) $L_{i}=\bar{L}(1+\rho)^{j}$

where $[$ is the loss in the first period and $\rho$ is the rate of growth in potential output, If $r=\rho$, the expression for $L$ simplifies to $\left(10^{1}\right) L=n E$ This is precisely the way we caiculated the discounted value of the cumulative output loss above for the Perry and Cagan equations. 
To simplify further, we assume $g_{j}$ is a constant $\bar{g}$ for all $i \geq n$. We then solve for the value of $\bar{g}$ which first equates the cost of unemployment and the gain from eradicating inflation -- the minimum value of the permanent per period gain from eradicating inflation that would justify incurring the transitional costs. The value of $\bar{g}$ for the Perry, Stein, and Cagan results are presented in Table 8 ; we calculated them under the assumption of a 3.3 percent discount rate and for two

TABLE 8

The Minimum Value of the Per Perjod Gain that Justifies Eradicating a 7.5 Percent Inflation Rate

$\begin{array}{lcc}\begin{array}{c}\text { Equation/ } \\ \text { Model }\end{array} & \text { Value of } \vec{g} \text { (billions of } 72 \$ \text { ) } \\ \text { Perry 1 } & 3.2 & 2.5 \\ \text { Perry 2 } & 73.0 & 57.0 \\ \text { Cagan } & 70.9 & 55.4 \\ \text { Stein 1 } & 16.6 & 13.0 \\ \text { Stein 2 } & 31.0 & 24.2 \\ & 25.4 & 19.8\end{array}$

alternative values of the Okun's Law coefficient $(3.2$ and 2.5 , respectively). The minimum value of $\vec{g}$ varies from $\$ 13$ billion per year based on Cagan's Phillips curve to $\$ 73$ billion based on the Perry's Phillips curve under a moderate policy.

Note that this analysis provides an alternative perspective on the case for gradualism. Under gradualism, the costs may be reduced if the Phillips curve is nontinear. But the benefits are also more gradual (in our analysis, postponed until inflation is eradicated). Thus, we find that although the costs are smaller under the gradual policy using the Perry equation (Perry 1), the size of the per period gain 
required to justify eradicating inflation is smaller under the more radical policy (Perry 2). The radical policy also yields a smaller minimum per period gain using the Stein model, although this result was expected in this case because the cost turned out to be lower in the radical case using stein's model.

The calculations reported above presumed that the gains from reducing inflation could be meaningfully represented as a fixed real sum per period. What if the gains are more meaningfully specified as a real sum which grows at the same rate as potential output? For example, the cost of a fully anticipated increase in inflation is generally measured by the reduction in the area under the demand curve for money balances as wealth owners reduce their demand for money in response to the associated rise in nominal interest rates. The decitine in demand for real money due to a rise in the interest rate is generally viewed as proportional to the overall scale of money holdings which, in turn, is determined by the level of transactions (e.g. reat income). The cost of a given rate of inflation and hence the benefits of eliminating the inflation may therefore grow at the rate of increase of potential output. In this case where $g$ is the value of the gain in period $n$ (the (8') $G=\sum_{i=n}^{\infty} \frac{\bar{g}(1+\rho)^{i}}{(1+r)^{i}}$

first period in which a gain is registered). For $p \geq r, G \rightarrow \infty$. This corresponds to the result recently derived by Feldstein (1979): if the cost of inflation grows at a rate equal to or greater than the discount rate, any positive initial gain (any $\bar{g}>0$ ) is sufficient to justify incurring any finite transitional cost! 
These results suggest that the case for anti-inflation policies should not be dismissed Iightly, even when there are large transitional costs of eradicating infiation. The range of the estimates of the cumlative output loss, the uncertainty about the adjustment in those results required to allow for the credibility effect, and the lack of a quantitative estimate of the cost of inflation makes it extremely difficult to make a meaning hl comparison of the costs and benefits of anti-inflation policy. It should not be supprising therefore that policymakers generally seem indecisive and often lacking in commitment to reduce inflation. Narrowing the range of estimates of output loss and developing a measure of the cost of inflation should be high on the priorities for macroeconomic research in the 1980 s.

\section{RULES VERSUS ACTIVISM}

The case against activism rests on two propositions. The first proposition is that the private sector of the economy is inherently stable. This is a major tenet of monetarism and suggests the absence of a need for stabilization policy. Indeed, monetarists generally contend that the instability observed in the economy results mainly from government rather than private sector decisions. The inherent stability of the private sector results in part from the absence of large and persistent exogenous shocks and in part from the fact that the shocks that do occur have relatively small and only temporary effects on output and eimployment as a consequence of the economy's built-in stability.

The second proposition in the case against activism is that even if the economy were subject to cumulative movements in output, employm ment and inflation relative to target levels, discretionary policy 
might only compound the instability rather than dampen it. The danger that policy will turn out to be destabilizing follows from the long inside lag, the long and variable outside lag, and the general uncertainty about the effect of policy on the economy.

The case for activist policy involves a rejection of the two propositions developed above; the economy needs to and can be stabilized by appropriate manipulation of policy instruments. The first proposition in support of policy activism, then, is that the economy is subject to substantial and persistent disturbances arising from the private sector. In addition, nommonetarists contend that policy can be implemented with sufficiently short inside lags and with sufficient precision qiven our understanding of the structure of the economy to yield an improvement in economic perfomance relative to a policy of a fixed rule.

Relevant empirical evidence on rutes versus activism includes:

(1) the relative size of exogenous impulses arising from policy and nonpolicy sources

(2) the degree of persistence in the response to such disturbances

(3) the ability of active policy to improve economic performance in the face of the disturbances.

Stability of the Private Sector

The issue of the stability of the private sector has been categorized as a fundamental difference between monetarists and the conventional Keynesian tenets (See Andersen (1973) and Mayer (1975)). Nevertheless, it appears to be an issue on which little, if any, relevant empirical evidence is available.

The evidence that is conventionally cited in response to the allegation that the Keynesian position regards the private sector as 
inherently unstable is the result of simulation experiments with various econometric modeis. These experiments suggest that the models are stable, usually exhibiting highly damped oscillations back to equilibrium following some shock (see klein (1973)). Such results under the postulated experimental conditions are probably a necessary condition, but not a sufficient condition to substantiate the monetarist proposition. We would need to look at the degree of damping under a policy of fixed rules relative to the damping under an endogenous policy with feedback from current economic developments. The case for rules is enhanced if endogenous policy reduces the degree to which disturbances are damped.

\section{Evidence from Model Simulations}

Discussions of the effectiveness of policies often focus on the size of policy mutipliers. Such measures of the leverage of policy on goal variables are critical to setting policy, but do not provide any evidence on the usefulness of discretionary policy unless they are zero. Indeed as Cooper and Fischer demonstrate, even if the policy instrument has a zero cumulative multiplier it may be useful as a stabilization tool as long as it has a nonzero short-run multiplier. More important is the predictability of the outcome of policy actions which is more closely related to the errors in forecasting the goal variables. The case for discretion, therefore, has little or nothing to do with the size of policy multipliers, unless there is some concern about moving the policy variables too far or too fast such as when a "penalty function" is added to the "goal function." The time pattern of the response as well as the predictability of the policy multipliers, on 
the other hand, do matter. Evidence on rules versus discretion, therefore, generally involve model simulations and these are most useful if allowance is made for uncertainty about the multipliers.

Below we review the evidence on the comparison of economic performance under rules and discretion based on simulations with macrow economic models. First we must define a set of alternative policies; four alternatives have been investigated.

1) Actual policy: Historical simulations in which policy instruments take on their historical values provide the benchmark of actual policy, discretion as it was implemented as opposed to what would have been optimal in the context of the model under consideration.

2) Fixed rules or rules without feedback: Simulations in which the policy instrument is constrained to grow at a constant rate provide evidence on the effect of fixed rules; for example, a constant rate of monetary growth as advocated by Friedman. In this case the policy instrument is totally independent of current economic developments.

3) Active rules or rules with feedback: An alternative to both discretion and fixed rules is an active rule or a rule which requires policy instruments to respond systematically to current economic developments. This approach introduces Phillips type ad hoc rules involving proportional and derivative controls. Sone experimentation is undertaken to identify "good" rules but short of full optimization. Such simulations can be viewed as a way of modeling systomatic discretionary policy without the blatant policy errors that in retrospect always mar the historical runs.

4) Optimal control: The benchmark for identifying the best that is possible under discretionary policy is an optimal control simulation in 
which policymakers are viewed as selecting a time path for their instruments that minimizes the losses associated with deviations of their goal variables from their target levels. It, therefore, requires intposing an explicit loss function including the designation of relative weights on competing objectives and solving the model subject to minimization of the losses. The solution allows the selection of an instrument path to reflect knowledge of the structural parameters of the model and forecasts of future performance based on current and past values of exogenous variablas and the dynamic structure of the model. A superior economic perfomance under such circumstances hardiy provides convincing support for discretionary policy, although it provides evidence of the potential for discretionary policy to improve economic performance.

The various policy regimes can be simulated in a number of different ways. In a deterministic simulation the error terms in the various estinated equations are set to zero. This immediately removes a potentially important source of instability in the private economy and should be expected to bias results in favor of fixed rules. There are two basic types of stochastic simulations reflecting the two sources of randon disturbances: the additive error terms in the estimated equations and the estimated coefficients. Simulations allowing for random additive error disturbances are generally labeled stochastic simulations while those that randomize both parameters and additive errors are referped to as fully stochastic simulations. 
Actual Policy Versus Fixed Monetary Growth Rules

Modigliani reports two simulations with a fixed monetary growth rule over the period beginning in 1959 and ending in mid-1971. In each case $M I$ is constrained to grow at a 3 percent annual rate. In the first simulation all shocks are eliminated by substituting constant trends or means for untrended exogenous variables. In the second, historical values of exogenous variables are employed. In the first case the monetary rule stabilizes the economy, but, allowing for historical shocks the economy "was distinctly less stable than actua" experience, by a factor of 50 percent $[p .12]$."

Eckstein investigates the implications of smooth growth in nonborrowed reserves over the period of 1964 through 1975. (Nonborrowed reserves grow at a 4 percent rate in ' 64 , accelerate $1 / 4$ percent point each year until they stabilize at a 6 percent rate during and after 1972). Eckstein finds that smooth growth in reserves does result in "a more stable growth pattern" but does not dramatically alter the overall results for economic performance.

Active Rules Versus fixed Rules

In a series of papers employing simulations with both the MPS and St. Louis mode1s, Cooper and Fischer (1972a, 1972b, 1974) compare Phillips type feedback control rules with fixed growth rate rules. They conclude that there are active rules which dominate fixed rules for both models, under deterministic, stochastic and fully stochastic simulations. The dominant active rules generally involving strong derivative controls and some proportional control. The criterion was the average standard deviation in the unemployment and inflation rates. 
For the St. Louis model, for example, the average standard deviations for each variable were reduced by about 20 percent in the deterministic simulations (over the period 56/I-68/IV), between $50-70$ percent in the stochastic simulations (over the same period) and by about 50 percent in the fully stochastic simulations (over the period 55/I - 71/TV). The improvement was more modest, however, in the MPS model, where the standard deviation of unemployment fell by $4-24$ percent and that of inflation by $7-32$ percent in stochastic simulations over the period $1956 / I-68 / 1 V$

optimal Control Simulations

There have been numerous attempts to compare fixed rules with optimal control simulations including Chow (1972), Garbade (1975), Cooper and Fischer (1975), Crane, Havenner and Tinsley (1976), and Crane, Havenner and Berry (1978). The first four studies find that fixed rules are uniformly inferior to optimal control (and generally inferior to historical policies). These studies use stochastic simulations but actual values of exogenous variables and, with the exception of Cooper and Fischer, constant parameter values. Garbade for example finds that "discretion," in the form of optimal control, reduces the expected loss by 50 percent compared to a fixed rule, a result in close agreement with chow. Garbade views his results as adding to the "accumulating evidence" of the gains associated with discretion "when a valid representation of the econony is avallable." But that, after all, is the major element in the controversy.

Cooper and Fischer find that their active rules perform quite well in relation to optimat control solutions using the st. Louis model. 
Costs are reduced by about 45 percent relative to fixed rules, but fixed rules outperform historica? policy in this case due in part to greater instability in instrument movements in the latter case. The Cooper-Fischer paper produces a possibly valuable insight about the relative performance of rules and discretion. Stochastic simulation requires multiple simulations for alternative realizations of the stochastic disturbances. They found that the poor overall performance of fixed rules resulted from their "spectaculariy bad" perfomance in replications where losses turned out to be above average for a 11 policies. Where average performance is good, on the other hand, fixed rules perform about as weil as optimal control. This may imply that optimal policy is nonlinear-restrained to fixed rules within a band around target values of goal variables and active only outside those bands. Thus, "fine tuning" is rejected, but activism in the face of a major disturbance has a substantial payoff.

This conclusion is reinforced by the Crane, Havenner and Tinsley study of the 1971/I-1974/II period using a condensed version of the MPS model, MINNIE. Optimal policy is not especially volatile after an initial aggressive expansionary policy in the first two quarters to offset the recession implicit in the initial conditions. The optimal policy again dominates fixed rules, in this case by about 40 percent; and fixed rules would have increased expected 1 losses by about 45 percent relative to historical policies.

Rational Expectations and the Limits of Activist Policy

The traditional arguments against activist poicy focused on the implications of long inside lags, long and variable outside lags, and 
multiplier uncertainty; there was a general emphasis on the limitations of policy in an enviroment characterized by insufficient knowledge of the economy's structure. The Lucas-5argent-Wallace rational expectations models suggest a dramatically different basis for fixed rules. These models suggest that policy is doomed to ineffectiveness in an environment in which economic agents have knowledge both about the structure of the economy and the way in which policy authorities respond to economic developments. In this case too much knowledge rather than too little knowledge underlies the ineffectiveness of policy. Real variables according to these models respond only to unanticipated price or inflation shocks. Systenatic policy, by definition, cannot produce surprises. Therefore, although there exists a trade-off between unanticipated inflation and unemployment, it cannot be systematically exploited by policy authorities; this is generally referred to as the neutrality proposition. The theoretical structure of these models and the implications of a number of qualifications, particularly the existence of nominal contracts, have been thoroughly developed in the paper by Taylor. The role, operational specification, and implications of rational expectations in macroeconomic models is the central issue in macroecononic theory today and empirical investigations of these models is certain to be the growth industry of the '80s. There are, however, only a handful of empirical studies to date that attempt to test the neutrality proposition.

McCallum (1979) in a recent survey of this literature notes that while "the formal evidence is not inconsistent with the neutrality proposition. . the power of existing tests is not high and, in any event, the evidence is not entirely clearcut." The two most important 
empirical studies are the Barro papers $(1977,1978)$ on the effect of unanticipated monetary growth on unemployment and output and Sargent's paper (1976) applying Sims and Granger tests for causality to movements in the unemployment rate, the money supply, government expenditures and other macro variables.

Barro estimates a reaction function to isolate unanticipated monetary growth and then examines the role of unanticipated and anticipated monetary change on unemployment and output. His results are remarkably one sided, supporting the hypothesis that only unanticipated policy actions affect real variables. But his empirical methodology has been convincingly critiqued by Small, Fischer (1978) and Gordon (1979). Sargent is somewhat more cautious in interpreting his findings as indicating that "the causal structure imposed on the data by the classical model. . . is not obscenely at variance with the data [p. 233]." We think this means the results are mixed, which indeed they are. There is some evidence, for example, that movements in the money supply "cause" movements in the unemployment rate (using the Granger test) and some evidence that it does not (using the sins test).

Summary

The evidence accumulated over the 170 s has has at best only a modest role in increasing the consensus over the gains associated with activist policy. The experience of the '70s has clearly eroded the optimism about the potential activist policy that characterized the apparent success of the 1964 tax cut and the long expansion of the ' 60 s. There is wider recognition today compared to the mid-7960s among proponents of active policy of the limitations of active policy and the 
difficulty of "fine tuning" the economy by responding to even smail departures of output and employment from target levels. Active policy, however, continues to have wide support in situations where a sizable displacement has occurred, as in the 1973-75 recession. On the other hand, many proponents of rules, such as Friedman (1968), also allow for the use of discretionary policy to offset "major disturbances [p. 14]." Therefore, the gulf between proponents of rules and activism is not nearly so great as it might at first appear. The optimal control studies have helped to emphasize the potential usefulness of aggressive policy action when initial conditions are far away from targets and the limited potential usefulness of activist policy in response to smaller displacements. This lesson is perhaps one on which proponents of rules and activism can agree.

\section{CONCLUSION}

As the '70s began, the monetarist-income expenditure controversy was a dominant theme in macroeconomics. Particularly after the MPS and other large scale models began churning out large values for monetary policy multipliers, the controversy focused in on the size of fiscal muttipliers, particularly the fiscal multipliers on nominal GNP. The econometric evidence of the "70s has not fully resolved this issue, i.e., there are those who continue to be persuaded by the st. Louis equation results. And while this evidence questioning the reliability of the fiscal multipliers in the St. Louis equation undoubtedly has reinforced the views of the skeptics, it has not necessarily shaken the confidence of the equation's supporters. 
As the '70s began, the orthodoxy of a Phillips curve embodying a stable trade-off was under an attack it did not survive. After a transitional period, evidence mounted in support of a vertical long-run Phillips curve. Thereafter, the issues contested have been the nature and sources of any short-run trade-off and the implications for the output loss of eradicating inflation. The econometric evidence from a wide range of sources and models suggests that monetary deceleration can eradicate inflation, but not quickly and not without large costs in terms of cumulative output loss. The major unresolved issue is the significance of the credibility effect and the degree of overestimation in the cumulative output loss due to the fallure to take into account the effect of recent policy actions and expected policy actions on inflation expectations.

While fine-tuning may have few advocates, the evidence from model simulations suggests there are likely to be considerable gains to activism when the economy is far away from targets and in response to very large shocks. Rules or activism remains an important issue although the case against activism has been broadened by the deveiopment of rational expectations market clearing models. 
REFERENCES

Alien, S. and T. Seaks, (forthcoming), "Nixon and Ford as Ex-Post Keynesians," Journal of Macroeconomics.

Andersen, L. (1973), "The State of the Monetarist Debate, "Federal Reserve Bank of $5 \mathrm{t}$. Louis Review (September).

Andersen, L. and K. Carlson (1970), "A Monetarist Model for Economic Stabilization," Federal Reserve Bank of St. Louis Review (Apri1), $7-25$.

Andersen, 1. and J. J. Jordan (1968), "Monetary ard Fiscal Actions: A Test of their Relative Importance in Economic Stabilization," Federal Reserve Bank of St. Louis Review (November), 11-24.

Andersen, P. (1979), "Rational Expectations Forecasts from Nonrational Models," dournal of Monetary Economics (January), 67-80.

Barro, R. (1977), "Unanticipated Monetary Growth and Unemployment in the United States," American Economic Review (March), 101-115.

Barro, R. (1978), "Unanticipated Money, Output, and the Price Level in the United States," Journal of Political Economy (Auqust), $549-580$.

Cagan, P. (1977), "The Reduction of Inflation and the Magnitude of Unemployment" in William Fellner ed., Contemporary Economic Problems 1977, American Enterprise institute, Washington, D.C., $41-50$.

Cagan, P. (1978), "The Reduction of Inflation by Slack Demand" in William Fellner ed., Contemporary Economic Problems 1978 , Anerican Enterprise Institute, Washington D.C., 13-45.

Carison, K. (1978), "Does the St. Louis Equation Now Believe in Fiscal Policy?" Federal Reserve Bank of St. Louis Review (February), $13-19$

Chow, G. (1972), "How Much Could Be Gained by Optimal Stochastic Control Policies?" Annals of Economic and Social Measurement (October), $391-406$.

Chow, G. (1977), "Usefulness of Imperfect Models for the Formulation of Stabilization Policies," Annals of Economic and Social Measurement (Spring).

Christ, C. (1975), "Judging the Performance of Econometric Models of the U.S. Economy," International Economic Review (February).

Congressional Budget office (1978), Understanding Fiscal Policy. 
Cooper, J. P. and S. Fischer (1975), "A Method of Stochastic Control of Nonlinear Econometric Models and an Application," Econometrica (January), 147-162.

Cooper, J. P. and 5. Fischer (1974), "Monetary and Fiscal Policy in a Fully Stochastic St. Louis Econometric Model, "Journal of Money, Credit and Banking (February), $1-22$.

Cooper, J. P. and S. Fischer (1972), "Simulations of Monetary Rules on the FRB-MIT-Penn Mode1, "Journal of Money, Credit and Banking (May), 384-396.

Cooper, J. P. and S. Fischer (1972), "Stochastic Simulation of Monetary Rules in Two Macroeconomic Models, ${ }^{\text {*3 }}$ Journal of American Statistical Association (December), 750-60.

Corrigan, E. C. (1970), "Measurement and Importance of Fiscal Policy Changes," Federal Reserve Bank of New York Monthly Review (June), $133-45$.

Crane, R., A. Havenner, and J. Berry (1978), "Fixed Rules versus Activism in the Conduct of Monetary Policy," American Economic Review (December), 769-783.

Crane, R., A. Havenner, and P. Tinsley (1976), "Optimal Macroeconomic Control Policies," Annals of Economic and Social Measurement (Spring), 191-204.

deleeuw, F. and E. Gramljoh (1969), "The Channels of Monetary Policy," Federal Reserve Bulletin, 472-91.

deleeuw, F. and E. Gramlich (1968), "The Federal Reserve-MIT Econometric Model," Federal Reserve Bulletin (January), 11-46.

deLeeuw, $F$. and J. Kalchbrenner (1969), "Monetary and Fiscal Actions: A Test of Their Relative Importance in Economic Stabilization -Comment," Federal Reserve Bank of St. Louis Review (Apri1), 6-11.

Dewald, W. and M. Marchon (1978), "A Modified FederaT Reserve of St. Louis Spending Equation for Canada, France, Germany, Ita1y, the United Kingdom, and the United States," Kredit und Kapital.

Eckstein, 0. (1978), The Great Recession, North Holland, Ansterdan.

Evans, M. K. and L. R. Klein (1968), The Wharton Econometric Forecasting Mode1, Economics Research Unit, University of Pennsy1vania, 2nd ed.

Feldstein, M. (1979), "The welfare Cost of Permanent Inflation and Optimal Short-Run Economic Policy," Journal of Political Economy (August), 749-767. 
Fellner, W. (1979), "The Credibility Effect and Rational Expectations Implications of the Gramlich Study," Brookings Papers on Economic Activity, 167-178.

Fischer, S. (1978), "On Activist Policy With Rational Expectations," National Bureau of Economic Research Working Paper.

Fischer, S. and F. Modigliani (1978), "Towards an Understanding of the Real Effects and Costs of Inflation," Weltwirtschaftliches Archiv, 810-833.

Friedman, B. (1977), "Even the St. Louis Model Now Believes in Fiscal Policy," Journal of Money, credit and Banking (May), 365-67.

Fromen, G. and L. Klein (1973), A Comparison of Eleven Econometric Models of the United States," American Economic Review Paper and Proceedings (May).

Fromm, G. and L. R. Klein (1976), "The NBER/NSF Model Comparison Seminar: An Analysis of Results, "Annals of Economic and Social Measurement, 1-28.

Garbade, K. (1975), "Discretion in the Choice of Macroeconomic Policies," Annals of Economic and Social Measurement (Spring), 215-238,

Goldfeld, S. and A. Blinder (1972), "Some Implications of Endogenous Stabilization Policy," Brookings Papers on Economic Activity, $585-640$.

Gordon, R. J. (1976), "Comments on Modigliani and Ando" in J. Stein, Monetarism, North Holland, Amsterdam, 52-66.

Gordon, R. J. (1979), "New Evidence that Fully Anticipated Monetary Changes Influence Real Output After A11," National Bureau of Economic Research Working Paper \#361.

Gordon, R. J. (1978), "What Can Stabilization Policy Achieve," American Economic Review (May), 335-341.

Gramlich, E. (1979), "Macro Policy Response to Price Shocks," Brookings Papers on Economic Activity, 125-766.

Gramlich, E. (1971), "The Usefulness of Monetary and Fiscal Policies as Discretionary Stabilization Tools," Journal of Money, Credit and Banking (May), 506-532.

Hymans, S. H. and H. T. Shapiro (1970), "The DHL-III Quarterly Mode? of the U.S. Economy," Research Seminar in Quantitative Economics, University of Michigan.

Klein, L. R. (1973), "Commentary on the Current State of the Monetarist Debate," Federal Reserve Bank of St. Louis Review (September). 
Lucas, R. E. (1975), "Econometric Policy Evaluations: A Critique" in $K$. Brunner and A. Meltzer, The Phillips Curve and Public Policy, North Holland, Amsterdam.

Mayer, T. (1975), "The Structure of Monetarism I," Kredit and Kapitat.

Mccallum, B. (1979), "The Current State of the Policy Ineffectiveness nebate," Anerican Economic Review (May), 240-245.

Modigliani, F. (1971), "Monetary Policy and Consumption" in Consumer Spending and Monetary Policy: the Linkages, Federal Reserve Bank of Boston, Boston.

Modigliani, F. (1977), "The Monetarist Controversy or Should We Forsake Stabilization Policies," American Economic Review (March), 1-19.

Modigliani, F. and A. Ando (1976), "Impacts of Fiscal Actions on Aggregate Income and the Monetarist Controversy in J. Stein ed., Monetarism, North Holland, Amsterdam.

Okun, $A_{+}$, "Efficient Disinflationary Policies," American Economic Review (May), 348-52.

Okun, A. (1972), "Fiscal-Monetary Activism: Some Analytical Issues," Brookings Papers on Economic Activity, 123-163.

Papademos, L. (1977), Optinal Aggregate Employment Policy, Ph.0. disser. tation, Massachusetts Institute of Technology.

Perry, G. (1978), "Stow]y the Wage Price Spiral: A Macroeconomic View," Brookings Papers on Economic Activity, pp. $659-291$.

Sargent, T. (1976), "A Classical Macroeconomic Model of the United States," Journal of Political Economy 207-237.

Sargent, T. and N. Wa11ace (1976), "Rational Expectations and the Theory of Economy Policy," Journal of Monetary Economics.

Schmidt, P. and R. Waud (1973), "The Almon Lag Technique and the Monetary versus Fiscal Policy Debate," Journal of the American Statistical Society (March), 11-19.

Silber, W. (1971), "The St. Louis Equation: 'Democratic' and "Republican" Versions and Other Experiments," Review of Economics and Statistics (November), 362-367.

Sma11, D. (forthcoming), "A Comment on Robert Barro's Unanticipated Money Growth and Unemployment in the United States," American Econonic Review.

Stein, J. (1978), "Inflation, Employment and Stagflation," Journal of Monetary Economics. 